\title{
How Tropical Pacific Surface Cooling Contributed to Accelerated Sea Ice Melt from 2007 to 2012 as Ice Is Thinned by Anthropogenic Forcing
}

\author{
IAN BAXTer, ${ }^{\mathrm{a}, \mathrm{b}}$ Qinghua Ding, ${ }^{\mathrm{a}, \mathrm{b}}$ AXEl Schweiger, ${ }^{\mathrm{c}}$ Michelle L'HeureuX, ${ }^{\mathrm{d}}$ STEPHen BaXter, ${ }^{\mathrm{d}}$

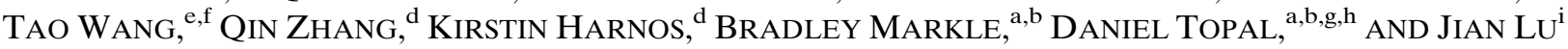 \\ ${ }^{a}$ Department of Geography, University of California, Santa Barbara, Santa Barbara, California \\ ${ }^{\mathrm{b}}$ Earth Research Institute, University of California, Santa Barbara, Santa Barbara, California \\ ${ }^{\mathrm{c}}$ Polar Science Center, Applied Physics Laboratory, University of Washington, Seattle, Washington \\ ${ }^{\mathrm{d}}$ NOAA/Climate Prediction Center, College Park, Maryland \\ ${ }^{\mathrm{e}}$ Earth System Science Interdisciplinary Center, University of Maryland, College Park, College Park, Maryland \\ ${ }^{\mathrm{f}}$ NASA Goddard Space Flight Center, Greenbelt, Maryland \\ ${ }^{\mathrm{g}}$ Research Center for Astronomy and Earth Sciences, Institute for Geological and Geochemical Research, Budapest, Hungary \\ ${ }^{\mathrm{h}}$ Department of Meteorology, Eötvös Loránd University, Budapest, Hungary \\ ${ }^{\mathrm{i}}$ Atmospheric Sciences and Global Change Division, Pacific Northwest National Laboratory, Richland, Washington
}

(Manuscript received 14 November 2018, in final form 6 September 2019)

\begin{abstract}
Over the past 40 years, the Arctic sea ice minimum in September has declined. The period between 2007 and 2012 showed accelerated melt contributed to the record minima of 2007 and 2012. Here, observational and model evidence shows that the changes in summer sea ice since the 2000 s reflect a continuous anthropogenically forced melting masked by interdecadal variability of Arctic atmospheric circulation. This variation is partially driven by teleconnections originating from sea surface temperature (SST) changes in the east-central tropical Pacific via a Rossby wave train propagating into the Arctic [herein referred to as the Pacific-Arctic teleconnection (PARC)], which represents the leading internal mode connecting the pole to lower latitudes. This mode has contributed to accelerated warming and Arctic sea ice loss from 2007 to 2012, followed by slower declines in recent years, resulting in the appearance of a slowdown over the past 11 years. A pacemaker model simulation, in which we specify observed SST in the tropical eastern Pacific, demonstrates a physically plausible mechanism for the PARC mode. However, the model-based PARC mechanism is considerably weaker and only partially accounts for the observed acceleration of sea ice loss from 2007 to 2012. We also explore features of large-scale circulation patterns associated with extreme melting periods in a long (1800 yr) CESM preindustrial simulation. These results further support that remote SST forcing originating from the tropical Pacific can excite significant warm episodes in the Arctic. However, further research is needed to identify the reasons for model limitations in reproducing the observed PARC mode featuring a cold Pacific-warm Arctic connection.
\end{abstract}

\section{Introduction}

Earth has warmed significantly over the past 40 years, and the fastest rate of warming has occurred in and around the Arctic (Serreze and Barry 2011; Bintanja et al. 2011; Vaughan et al. 2013; Fyfe et al. 2013; Cohen et al. 2014; Perlwitz et al. 2015; Screen and Francis 2016). The warming of northern high latitudes at a rate of almost twice the global average, known as Arctic amplification, is associated with sea ice loss, glacier retreat, permafrost degradation, and expansion of the melting season (Post et al. 2013; Overland and Wang 2013;

Corresponding author: Qinghua Ding, qinghua@uscb.edu
Stroeve et al. 2014; Notz and Stroeve 2016). Since the mid-2000s, summer sea ice has exhibited a rapid decline, reaching the record minima in September sea ice area in 2007 and 2012. However, after the early 2010s, the downward trend of minimum sea ice area appears to decelerate (Swart et al. 2015). This apparent slowdown, and the preceding acceleration in the rate of sea ice loss are puzzling in light of a steadily increasing rate of greenhouse gas emissions of $2 \mathrm{ppm} \mathrm{yr}^{-1}$ in the past decade that provides a steady climate forcing. Internal variability of the climate system (Kay et al. 2011; Day et al. 2012; Ding et al. 2014, 2017, 2019; Meehl et al. 2018) or stabilizing feedbacks generating a temporary recovery (Tietsche et al. 2011) are likely explanations. 
Recent studies suggest that over the past four decades, low-frequency internal climate variability may have been as important as anthropogenic influences on observed Arctic sea ice decline (Kay et al. 2011; Wettstein and Deser 2014; Zhang 2015; Screen and Francis 2016; Stroeve and Notz 2018). Ding et al. $(2017,2019)$ suggest that a large part of the observed sea ice decline in recent decades is linked to a trend in the Arctic atmospheric circulation that is partially due to internal variability. This internally driven circulation trend, driving a barotropic high pressure anomaly in the Arctic, has warmed and moistened the Arctic atmosphere, increased clear-sky downwelling longwave radiation, and accelerated sea ice melt during boreal summer. A possible mechanism contributing to these changes in Arctic circulation is a teleconnection generated by low-frequency variability in sea surface temperatures (SST) and lower-latitude convection (Lee 2012; Ding et al. 2014; Trenberth et al. 2014; Lee et al. 2017; Meehl et al. 2018; Bevis et al. 2019). However, until only recently, studies focusing on the role of internal variability in modulating recent sea ice loss have primarily targeted processes within the Arctic (Lee et al. 2011; Lee 2012; Cvijanovic et al. 2017). In this paper, we focus on the increased sea ice loss from 2007 to 2012 and examine the role of teleconnections between the Arctic and tropical SSTs in explaining this change. We hypothesize that accelerated melt during this period, followed by a period where the impact of this mode weakens, creates the appearance of a decade long "pause" in summer sea ice loss. An improved understanding of the drivers and responses in this teleconnection has important implications for the interpretation of recent Arctic climate change and future projections, including answering the question of when we will see the first ice-free summer in the Arctic. Improvements in decadal prediction of Arctic sea ice also hinge on the identification of remote sources of internal variability (Mahlstein and Knutti 2012; Overland et al. 2012; Jahn et al. 2016; Swart 2017; Screen 2018).

\section{Data and methods}

\section{a. Reanalysis and sea ice data}

We calculate changes in atmospheric circulation, temperature, humidity and longwave radiation flux from 1979 to 2017 using reanalysis data from ERA-Interim (Dee et al. 2011). Sea surface temperatures are obtained from ERSSTV5 (Huang et al. 2017) and precipitation is from the Global Precipitation Climatology Project (GPCP; Huffman et al. 2009). Sea ice area and extent are derived from the National Snow and Ice Data Center (NSIDC) consisting of monthly data from November 1978 to the present (Cavalieri et al. 1996; Fetterer and Knowles 2004).
TABLE 1. 27 climate models in the CMIP5 historical+RCP8.5 experiments used to examine the forced response of the climate system to anthropogenic and natural external forcing, along with the number of atmospheric horizontal grids.

\begin{tabular}{lrr}
\hline \hline CMIP5 model designation & $n x$ & $n y$ \\
\hline ACCESS1.0 & 192 & 144 \\
ACCESS1.3 & 192 & 144 \\
BCC-CSM1.1 & 128 & 64 \\
BCC-CSM1.1-m & 320 & 160 \\
CanESM2 & 128 & 64 \\
CCSM4 & 288 & 192 \\
CESM1-CAM5 & 288 & 192 \\
CSIRO-Mk3.6.0 & 192 & 96 \\
FGOALS-g2 & 128 & 60 \\
GFDL CM3 & 144 & 90 \\
GFDL-ESM2G & 144 & 90 \\
GFDL-ESM2M & 144 & 90 \\
GISS-E2-H & 144 & 89 \\
GISS-E2-H-CC & 144 & 89 \\
GISS-E2-R & 144 & 89 \\
HadGEM2-CC & 96 & 73 \\
HadGEM2-ES & 192 & 144 \\
INM-CM4 & 180 & 120 \\
IPSL-CM5A-MR & 144 & 143 \\
IPSL-CM5B-LR & 96 & 96 \\
MIROC-ESM & 128 & 64 \\
MIROC-ESM-CHEM & 128 & 64 \\
MIROC5 & 256 & 96 \\
MPI-ESM-LR & 192 & 96 \\
MPI-ESM-MR & 192 & 128 \\
NorESM1-M & 144 & 144 \\
NorESM1-ME & & \\
\hline
\end{tabular}

Sea ice area is first calculated for each ocean grid as the product of ice concentration and grid element area. The total sea ice extent is then calculated as the sum of the area of all grid cells containing greater than $15 \%$ sea ice concentration. We use this total sea ice area and extent to measure the sea ice change in the past four decades. In this study, we focus on changes of sea ice area in the past 40 years given the reliability of satellite data in measuring sea ice area change.

\section{b. CMIP5, CESM-LENS, and MPI-Grand Ensemble}

We use monthly sea ice area from 40 realizations and 100 realizations, each with slightly perturbed initial conditions, from the historical and future projection (RCP8.5) experiments of the CESM Large Ensemble Community Project (LENS) (Kay et al. 2015) and MPI Grand Ensemble (Grand-Ens; Giorgetta et al. 2013), respectively. We also examine the 27 climate models (Table 1 ) in the CMIP5 database (Taylor et al. 2012) to estimate the sea ice response to historical and future external forcing (RCP8.5). We focus our analysis on the historical satellite era from 1979 to 2017 to allow comparison of ensemble means of simulated sea ice area trends with trends from 
observations. We also use an 1800-yr CESM preindustrial simulation (Kay et al. 2015) to understand large-scale circulation features associated with extreme Arctic sea ice melting episodes in the absence of anthropogenic forcing.

\section{c. Model experiments}

Additionally, we perform experiments using the ECHAM4.6 atmospheric general circulation model, at horizontal resolution of T42 $\left(\sim 2.8^{\circ}\right.$ latitude $\times 2.8^{\circ}$ longitude) with 19 vertical levels (Roeckner et al. 1996). We couple the ECHAM4.6 to a slab ocean (Ding et al. 2014), whereby the ocean is represented as boxes of water of uniform specified depth $(50 \mathrm{~m})$. A simple, thermodynamic-only sea ice model is included when the ocean temperature reaches the freezing point. The ocean temperature or sea ice condition at each grid point is affected only by heat exchange across the airsea interface; there is no direct communication between adjacent ocean grid points, nor is there any representation of the deep ocean. In addition, a cyclostationary climatological heat flux is added to the ocean temperature tendency equation to maintain a seasonal cycle of ocean temperature and sea ice condition that is close to that observed in the present day (1979-99). Two pacemaker experiments are conducted with a specification of SST in the tropical east-central Pacific (ECP; see also Fig. 8 b) and SST are interactively generated elsewhere by coupling with the slab ocean. In the control run, we place 1979-2017 (climatological) observed monthly SST (with a 12-month annual cycle) derived from ERSST in the ECP domain $\left(25^{\circ} \mathrm{S}-30^{\circ} \mathrm{N}, 145^{\circ}-285^{\circ} \mathrm{E}\right)$. To examine the impacts of tropical ECP SST in regulating recent circulation change in the Arctic, we specify 6-yr (2007-12) averaged monthly SST in the pacemaker domain. Anthropogenic forcing is fixed at a constant level in both experiments. We integrate the two runs for 40 years individually and then calculate the difference of the two simulations using the last 30 years, with the first 10 years discarded as a spinup. Since individual years are largely independent, the individual years are equivalent to ensemble members and the 30 -yr averages are equivalent to ensemble means. Differences between the control and SST anomaly run then allow us to assess the impact of SST anomalies during 2007-12. We conduct two additional experiments, using the same 40 -yr pacemaker methodology, expanding the domains of our prescribed SST to the entire tropics and the North Pacific.

\section{d. Maximum covariance analysis}

Maximum covariance analysis (MCA) is used to determine the primary covarying patterns of Arctic atmospheric circulation and tropical SSTs. MCA analysis uses singular value decomposition of a covariance matrix between June-August (JJA) 200-hPa geopotential height and SSTs (Bretherton et al. 1992; Wallace et al. 1992). The leading patterns calculated using this method show the time series and spatial patterns of the two fields that are optimally coupled.

\section{e. Wave activity analysis}

Wave activity analysis (Plumb 1985) is used to reveal stationary Rossby wave energy propagation. The wave flux vector provides direct information on the flux of wave activity, which is parallel to the group velocity of quasi-stationary Rossby waves. This diagnostic tool is well suited to detecting propagating large-scale, quasistationary Rossby waves.

\section{f. Significance of correlation}

The statistical significance of the correlation coefficient accounts for the autocorrelation in the time series by using an "effective sample size" $N^{*}$ (Bretherton et al. 1999):

$$
N^{*}=N \frac{1-r_{1} r_{2}}{1+r_{1} r_{2}}
$$

where $N$ is the number of available time steps and $r_{1}$ and $r_{2}$ are lag-one autocorrelation coefficients of each variable. A confidence level of $95 \%$ is used in this study to determine the significance of correlations and composites. We also conduct a Monte Carlo test to recheck the statistical significance of the calculated correlations (Livezey and Chen 1983). In this test, 1000 white-noise sea ice time series spanning 39 years are generated and correlated with JJA SST from 1979 to 2017. The 1000 correlations are sorted in increasing order at each ocean grid point and the mean of their 97.5 th and 2.5 th percentiles are used as the correlation threshold at $95 \%$ confidence level. This new threshold at each grid point will be used along with the thresholds determined by the first method (whichever is greater) to determine the significance of correlations between observed September sea ice with JJA SST.

\section{Prominent summer warming and sea ice melting in the Arctic from 2007 to 2012}

\section{a. Changes in the September total sea ice area}

September total sea ice area over the past four decades has exhibited an overall decline of -0.77 million $\mathrm{km}^{2}$ decade $^{-1}$, which is faster than the simulated sea ice decline in the ensemble means of CMIP5 ( -0.55 million $\mathrm{km}^{2}$ decade $\left.^{-1}\right)$, LENS ( -0.6 million $\mathrm{km}^{2}$ decade $^{-1}$ ), and Grand-Ens $\left(-0.48\right.$ million $\mathrm{km}^{2}$ decade $\left.^{-1}\right)$. The observed decline exhibits varying rates of change from decade to decade that are not seen in the ensemble means of the simulations (Fig. 1a), indicating a strong interdecadal 
a September total sea ice area

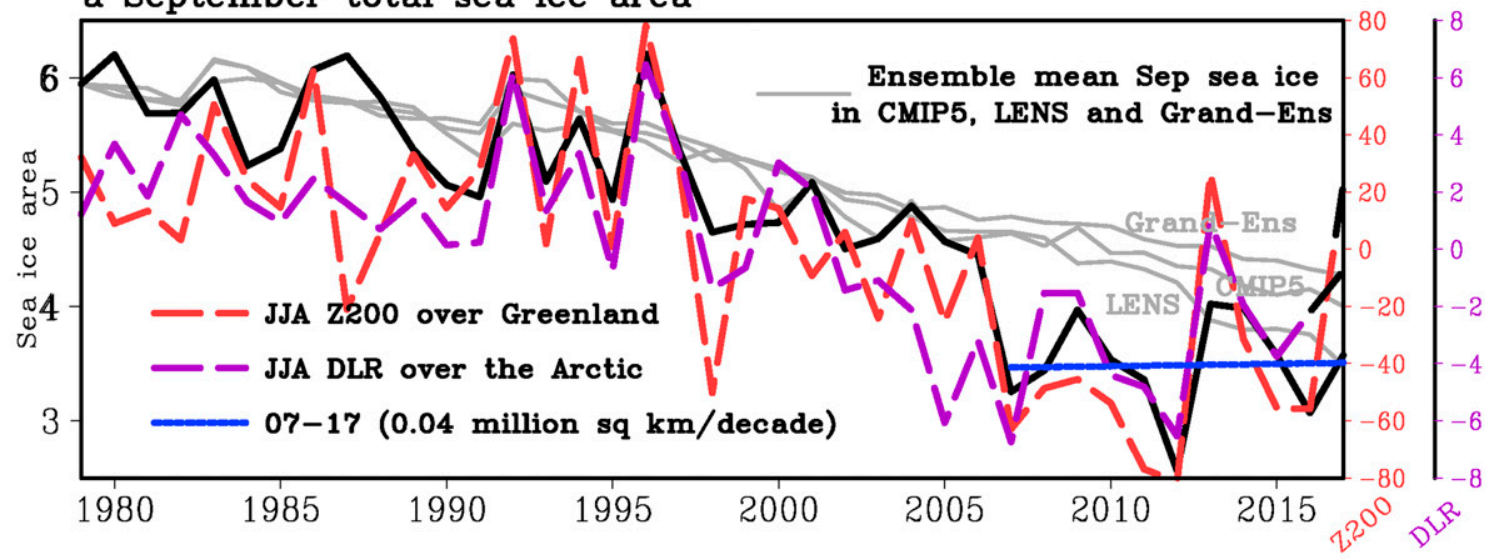

b Trends of Sep sea ice (any periods >10yr)

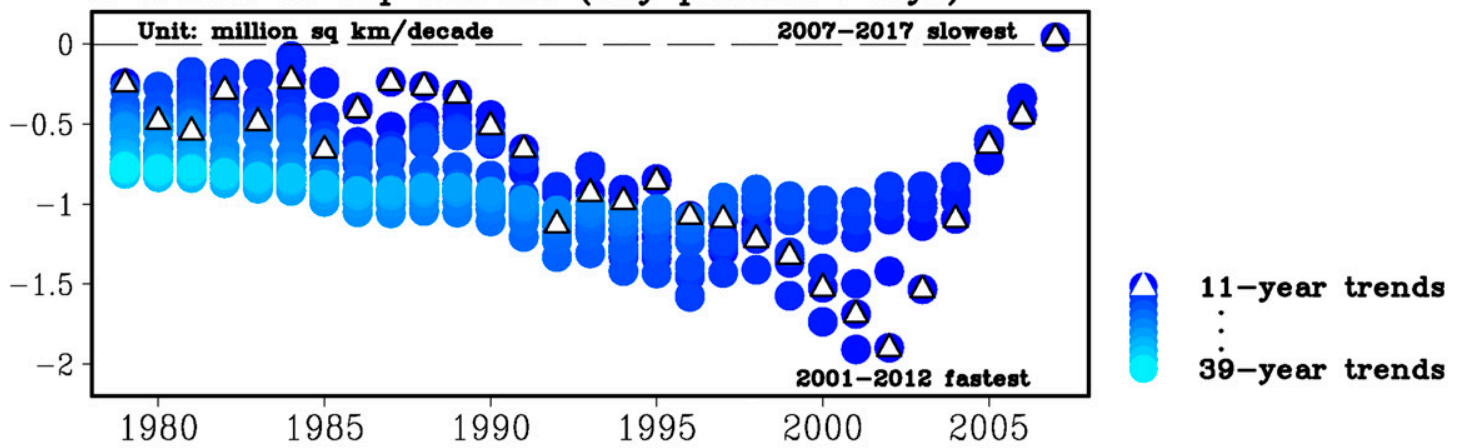

Trends during 79-06
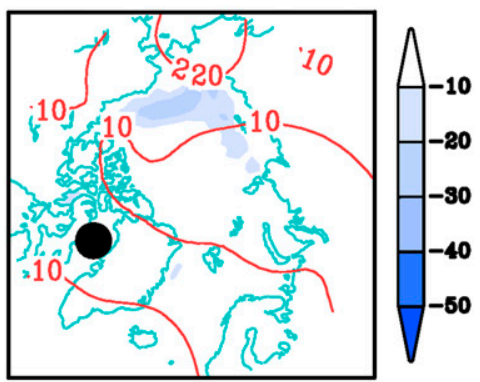

Anomalies during 07-12
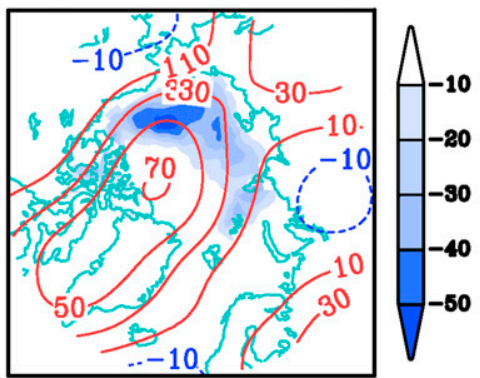

Anomalies during 13-17
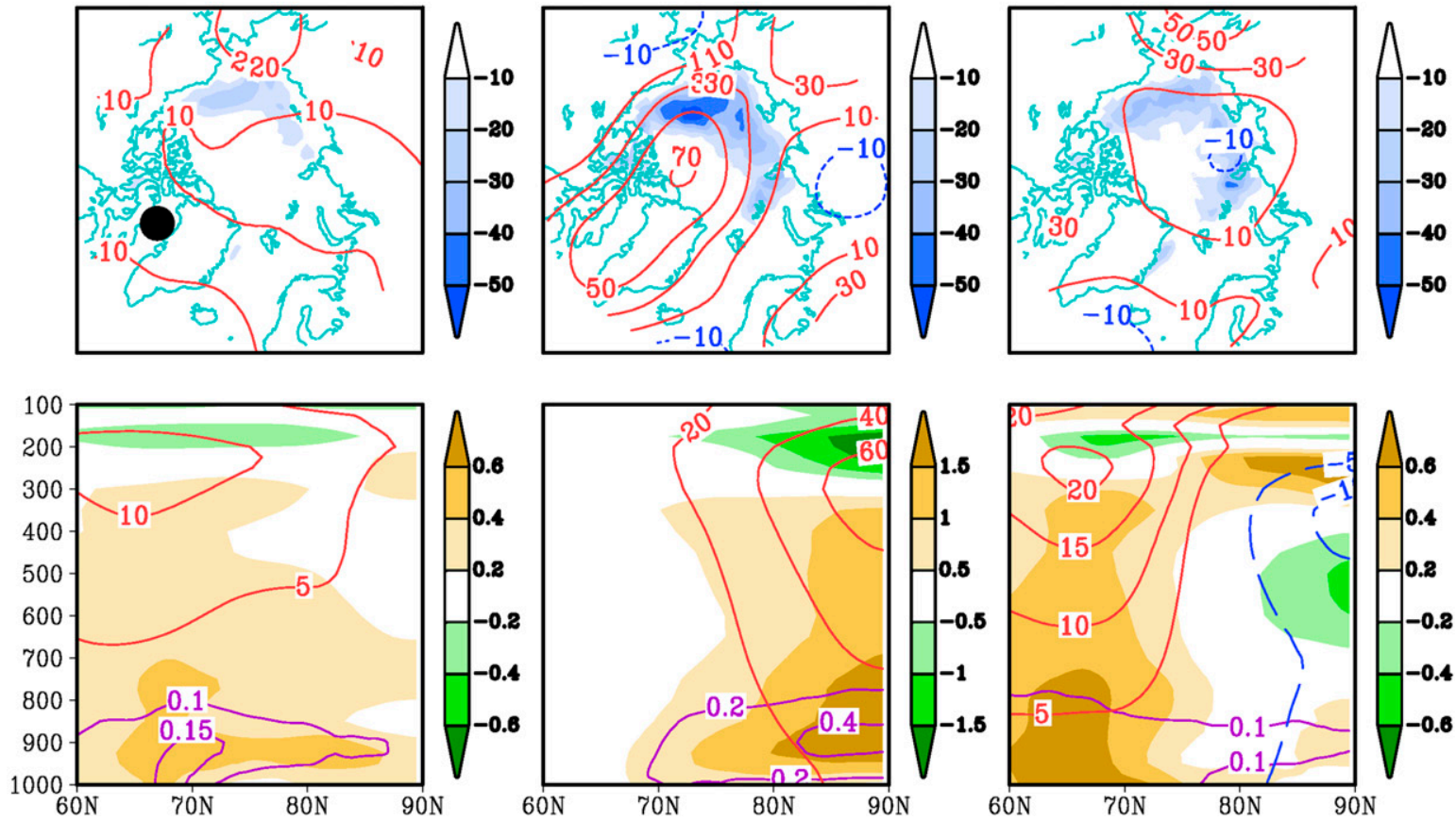

FIG. 1. (a) NSIDC September sea ice area index (1979-2017, unit: million km² black line) and its linear trend from 2007 to 2017 (blue line), simulated September sea ice area index from CMIP5, LENS, and Grand-Ensemble (1979-2017, unit: million km², gray lines), and observed ERA-I JJA Z200 (unit: m, the sign of Z200 is reversed) over Greenland (denoted as the black dot in the left panel of the third row) and ERA-I JJA surface DLR (unit: $\mathrm{W} \mathrm{m}^{-2}$, the sign of DLR is reversed) in the Arctic averaged over the area north of $70^{\circ} \mathrm{N}$. All simulated September sea ice area indices are shown beginning at the same initial area as observations for visual comparison. (b) All 
component of internal sea ice change (Winton 2011; Rosenblum and Eisenman 2017). In particular, the observed trend over the most recent epoch, 2007 to 2017, shows a near-zero trend $\left(+0.04\right.$ million $\mathrm{km}^{2}$ decade $\left.{ }^{-1}\right)$ (Fig. 1a). The recent slowdown of the trend was previously recognized by Swart et al. (2015), examining only 2007 to 2013, and is shown here to persist into 2017 and even into 2018 (3.56 million $\mathrm{km}^{2}$ ) (Fig. 1a).

To better understand internal variability of sea ice change since 1979 , we calculate the observed rate of change over all possible decadal periods longer than 10 years between 1979 and 2017 using a moving window (Fig. 1b). In this way, we can objectively find the slowest and fastest interdecadal variations of sea ice in the past 39 years over any possible time length and examine why they behave differently. There are two prominent periods of sea ice decline seen in the past four decades that differ the most in terms of the sea ice change rate in each period: a $11-y r$ period of the slowest decline with near-zero trend from 2007 to 2017 and a 12-yr period of the strongest decline from 2001 to 2012. The two periods overlap from 2007 to 2012, which was a period with particularly little summer sea ice including two record minimum sea ice area years in 2007 and 2012. It is this period (2007-12) of low summer sea ice area that causes the strongly contrasting trend magnitudes between the two decade-long periods (2001-12 vs 2007-17). In fact, any trends that include this period are dominated by the enhanced melting over this 6-yr period (Fig. 1b). The 2007-12 period is also the key episode in which the trends of the ensemble means from climate simulations, our best representation of the anthropogenically forced signal, diverge the most from the observed total sea ice area index (Fig. 1a). We therefore focus on this 6-yr period and attempt to understand the mechanisms that brought about its low summer sea ice area. To put this period into the context of the last 39 years, we split the entire record into three periods (1979-2006, 2007-12, and 2013-17). We then calculate trends of atmospheric variables and SST during the first period and compare them with the anomalies (vs 39-yr climatology) during 2007-12 and
2013-17 to examine how the patterns in the subsequent two periods enhance or mask long-term trends from 1979 to 2006.

\section{b. Local Arctic atmospheric changes in summer}

The summertime (JJA) 200-hPa geopotential height (Z200) around Greenland and downward longwave radiation (DLR) in the Arctic exhibit a very coherent temporal variation with the change of total September sea ice area over the past 39 years on both year-to-year and low-frequency time scales (Figs. 1a and 2a). Consistent with sea ice decline, Z200 and DLR (the signs of Z200 and DLR are reversed in Figs. 1a and 2a) also peak from 2007 to 2012, following a period of steady increase from the 1990s to 2006. Z200 and DLR then decline or show near-zero trend after 2012. Examining the spatial patterns of Z200 and sea ice changes (third row in Fig. 1) in the three periods shows that the largest height increase occurred from 2007 to 2012 over the region extending from Greenland toward the North Pole, coinciding with accelerated sea ice melt along the Russian side of the basin. Then, in the past five years since 2012, summer warming in the Arctic was mostly limited to areas south of $70^{\circ} \mathrm{N}$ and even exhibits a cooling tendency at $600 \mathrm{hPa}$ at the northern most latitudes (Fig. 1, bottom row). Although September sea ice area is smaller than the $39-y r$ average during the recent 5 years (2013-17), the reduction rate of sea ice area is much weaker $\left(+0.29\right.$ million $\left.\mathrm{km}^{2}\right)$ than that from 2007 to 2012. Zonal mean vertical profiles of JJA geopotential height, temperature, and humidity also exhibit a strong increase during 2007-12 over the Arctic. A return of the vertical structure to the pattern that dominated from 1979 to 2006, and even slightly negative geopotential anomalies in the central Arctic, is then observed in the most recent period (2013-17; Fig. 1). Sea ice variability over the three periods therefore maps onto the previously identified mechanism by which variability of Arctic atmospheric circulation, as well as resulting humidity and downwelling longwave radiation, affects September sea ice minima (Ding et al. 2017; Wernli and Papritz 2018).

\footnotetext{
possible linear trends 11 years (denoted by triangles) or longer in NSIDC Arctic September sea ice area (blue dots, unit: million $\mathrm{km}^{2}$ decade $^{-1}$ ). The time axis indicates the starting year of decadal-long periods. The period with the fastest decline is $2002-12$ and the slowest decline is observed for 2007-17. (third row) Linear trends in ERA-I JJA Z200 (contour, unit: $\mathrm{m} \mathrm{decade}^{-1}$ ) and September sea ice concentration (shading, unit: \% decade ${ }^{-1}$ ) for (left) 1979-2006 and the average from (middle) 2007-12 and (right) 2013-17 minus the 39-yr (1979-2017) long-term average. (fourth row) Zonal mean latitude-vertical profile of ERA-I JJA linear trends of height (red/dashed blue contour, unit: $\mathrm{m} \mathrm{decade}{ }^{-1}$ ), temperature (shading, unit: ${ }^{\circ} \mathrm{C} \mathrm{decade}{ }^{-1}$ ), and humidity (purple contour, $\mathrm{unit}_{\mathrm{g} \mathrm{kg}}^{-1} \mathrm{decade}^{-1}$ ) for (left) 1979-2006 and anomalies from the long-term (1979-2017) average for (middle) 2007-12 and (right) 2013-17.
} 


\section{a Detrended sea ice, Z200 and DLR time series}

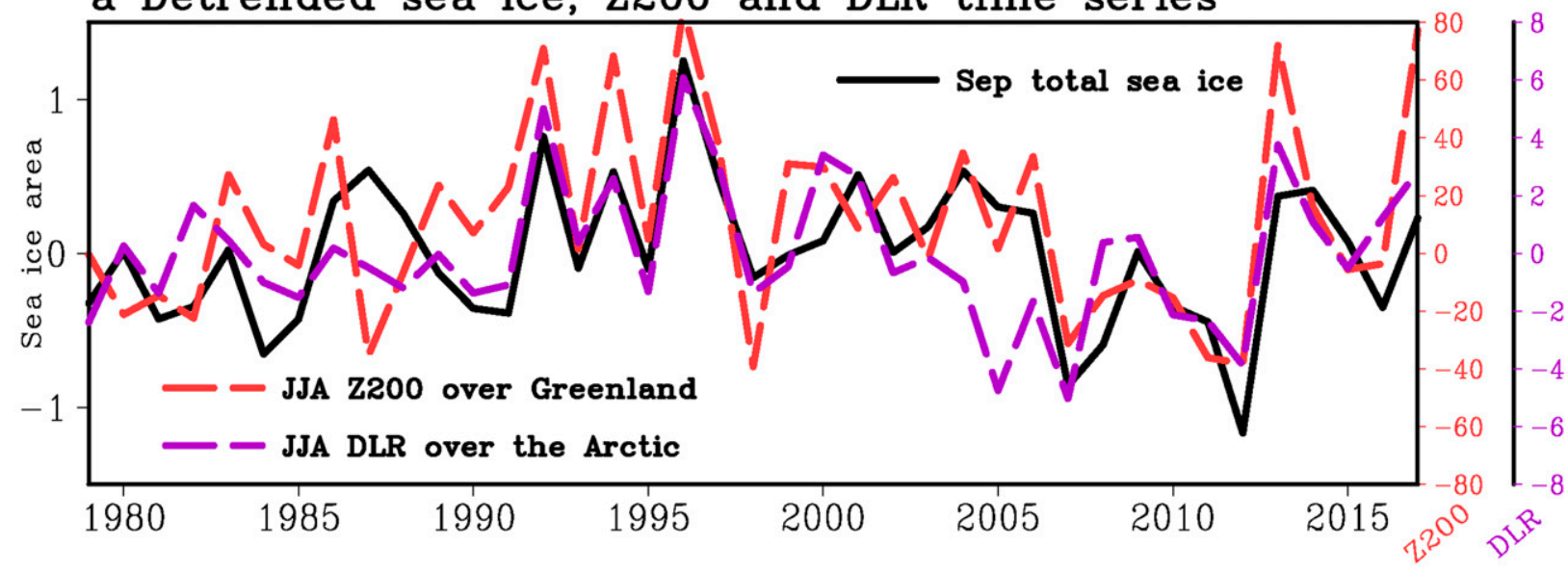

\section{b Zonal mean height}
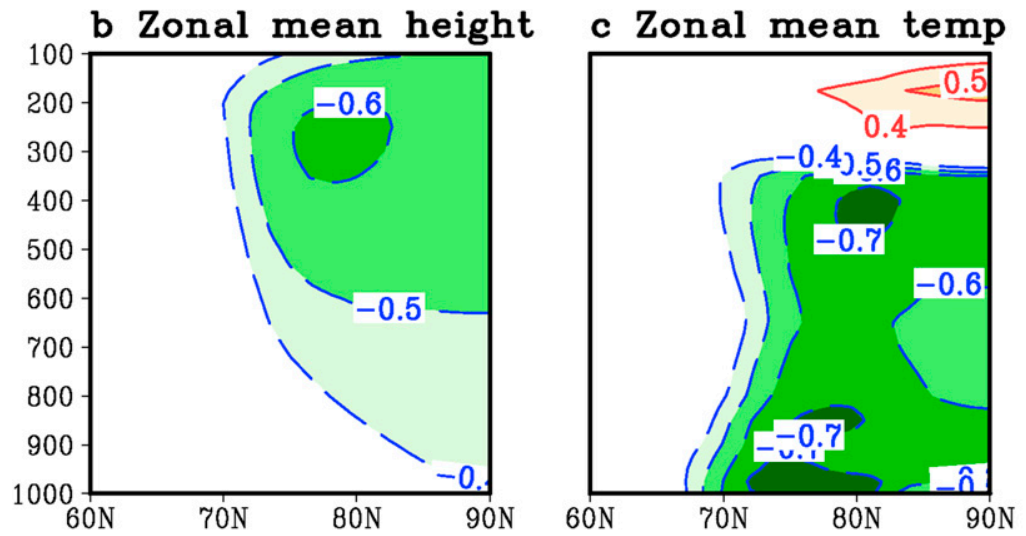

d Zonal mean hum
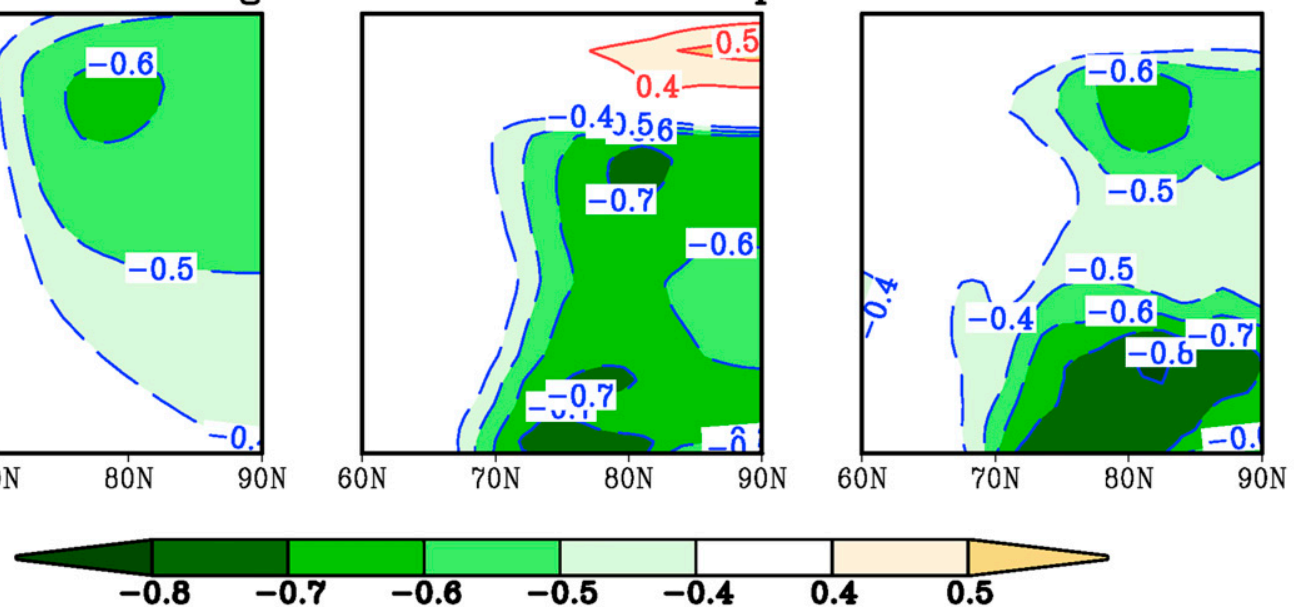

FIG. 2. (a) Detrended September total sea ice area index (solid black line, unit: million $\mathrm{km}^{2}$ ), JJA Z200 over Greenland (dashed red line, unit: $\mathrm{m}$ ), and JJA DLR over the Arctic (dashed purple line, $\mathrm{W} \mathrm{m}^{-2}$ ) from 1979 to 2017 derived from Fig. 1a. Sign of JJA Z200 and DLR are reversed. Correlation of detrended JJA zonal mean (b) geopotential height, (c) temperature, and (d) specific humidity with the detrended September total sea ice area index from 1979 to 2017.

The local mechanism linking the summertime Arctic atmosphere and September sea ice is highlighted by the time series of detrended sea ice, Z200 and DLR and the correlation between detrended JJA zonal mean atmospheric variables and September total sea ice area (Fig. 2) for the 39-yr period. These correlations highlight the strong connection between September sea ice and the preceding JJA upperlevel geopotential height $(r \approx 0.6$,$) tropospheric tem-$ perature $(r \approx 0.7-0.8)$, and humidity $(r \approx 0.7-0.8)$. These atmospheric variables are so closely related to sea ice because the large-scale circulation patterns, such as barotropic high pressure over the Arctic, can cause strong adiabatic descent of air that warms the lower troposphere and increases its ability to hold more moisture within the Arctic. This combination of a warmer and more humid atmosphere increases downward longwave radiation and leads to increases in sea ice melt as well as favors sea ice drift out of the basin (Ding et al. 2017; Yang and Magnusdottir 2018; Olonscheck et al. 2019).

\section{c. Global circulation and tropical SST and precipitation changes}

Different lines of evidence suggest that Arctic circulation changes in the past three to four decades partly have tropical origins (Ding et al. 2014; Trenberth et al. 2014; Meehl et al. 2018; Screen and Deser 2019). Figure 3 shows the linear trend of JJA Z200, sea surface temperature, precipitation, and upper-level divergence trends in the NH from 1979 to 2006 and the anomalies from 2007 to 2012 and 2013 to 2017. SST trends from 1979 to 2006 show a basin-wide warming across the Pacific, except in the ECP, accompanied by decreased precipitation, 


\section{9 to 2006}
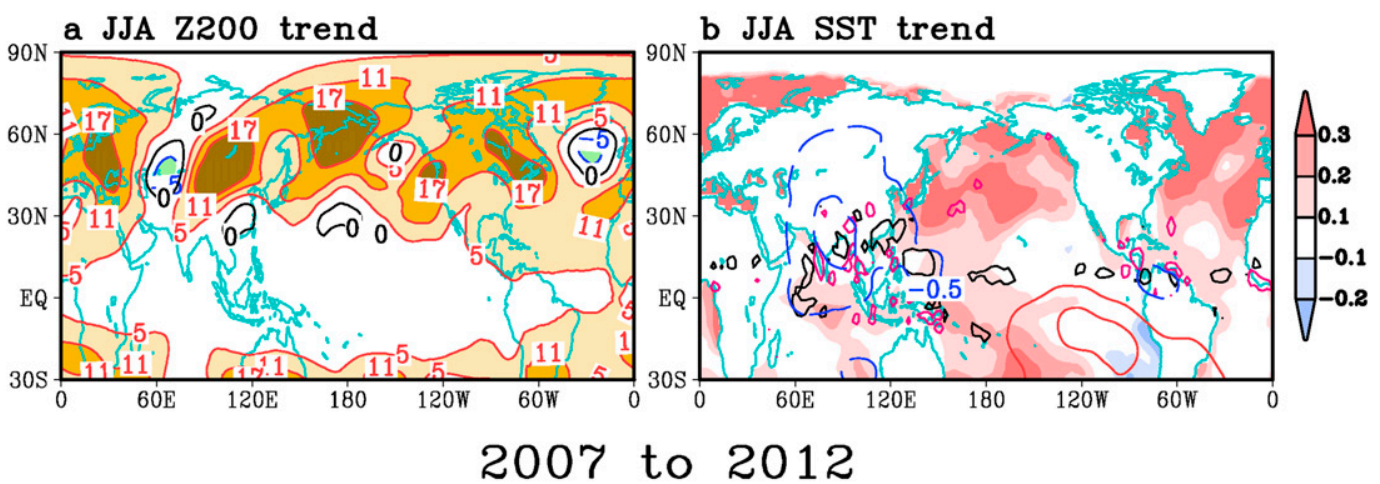

c JJA Z200 anomaly
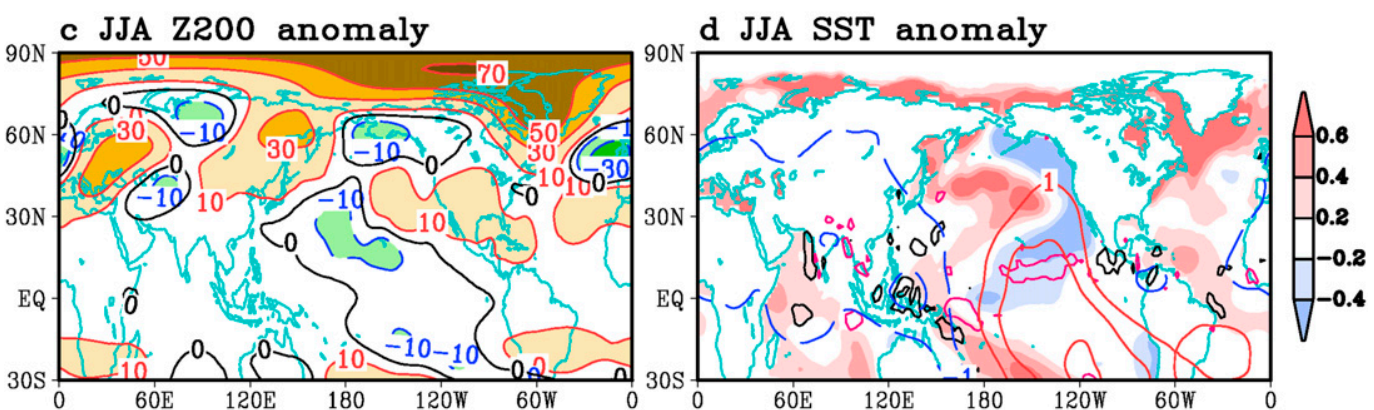

2013 to 2017

e JJA Z200 anomaly

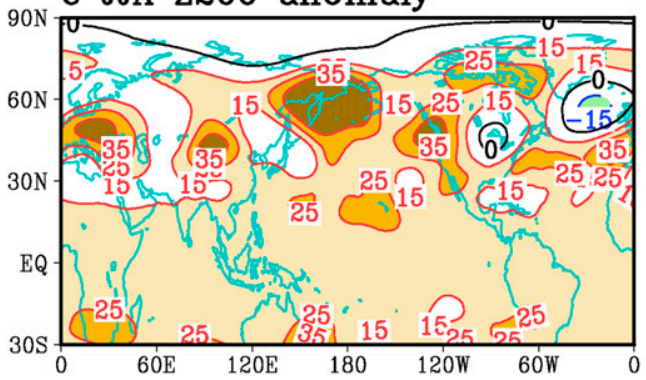

f JJA SST anomaly

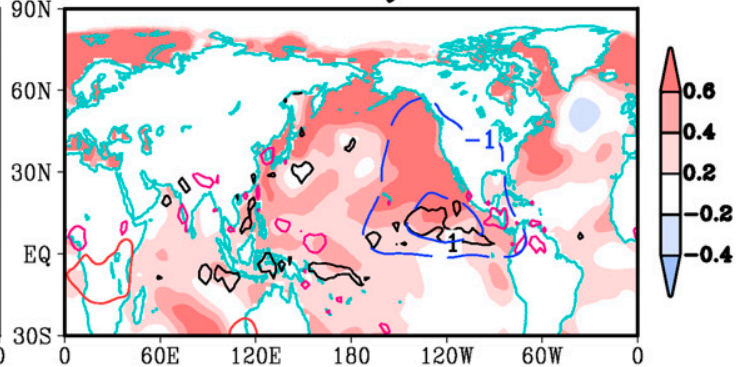

FIG. 3. (top) Linear trend in ERA-I JJA (a) Z200 (unit: $\mathrm{m} \mathrm{decade}^{-1}$ ) and (b) JJA SST from ERSST (shading, unit: ${ }^{\circ} \mathrm{C}$ decade ${ }^{-1}$ ), 200-hPa velocity potential (red solid/blue dashed contour, unit: $10^{6} \mathrm{~m}^{2} \mathrm{~s}^{-1} \mathrm{decade}^{-1}$ ), and precipitation (black/purple solid contours, unit: $0.5 \mathrm{~mm} \mathrm{decade}^{-1}$, purple contours indicate decreased precipitation) for 1979-2006. (middle) 2007-12 average minus the 1979-2017 long-term average in (c) JJA Z200 (unit: m) and (d) JJA SST (shading, unit: ${ }^{\circ} \mathrm{C}$ ), 200-hPa velocity potential (red/dashed blue contour, unit: $10^{6} \mathrm{~m}^{2} \mathrm{~s}^{-1}$ ), and precipitation (black/purple contours, unit: $1 \mathrm{~mm}$ decade $^{-1}$ ). (bottom) 2013-17 average minus the 1979-2017 long-term average in (e) JJA Z200 (unit: m) and (f) JJA SST (shading: ${ }^{\circ} \mathrm{C}$ ), 200-hPa velocity potential (red/dashed blue contour, unit: $10^{6} \mathrm{~m}^{2} \mathrm{~s}^{-1}$ ), and precipitation (black/purple contours, unit: $1 \mathrm{~mm} \mathrm{decade}{ }^{-1}$ ). Positive velocity potential (red contour) indicates a convergence. Thin black contours indicate positive precipitation trends and anomalies.

upper-tropospheric convergence over the eastern Pacific, and a circumglobal-type wave train propagating along the midlatitude westerly jet (Figs. 3a,b). This circumglobal wave feature is suggested to be partly a result of Arctic amplification in summer (Coumou et al. 2018). During 2007-12, SST cooling emerged over the ECP, likely contributing to strong local reductions in precipitation and also upper-level convergence, which may act as a significant
Rossby wave source generating a great circle-like wave train from the tropics to the Arctic and thus the prominent high pressure anomaly over the Arctic (Figs. 3c,d). After 2013, SST anomalies in the tropics returned to a state with warming almost everywhere (Figs. 3e,f). Correspondingly, the upper-level circulation over the tropical eastern Pacific exhibits an increased precipitation and divergence anomaly with the midlatitude circulation pattern returning to that 
Corr. of Sep sea ice with JJA SST
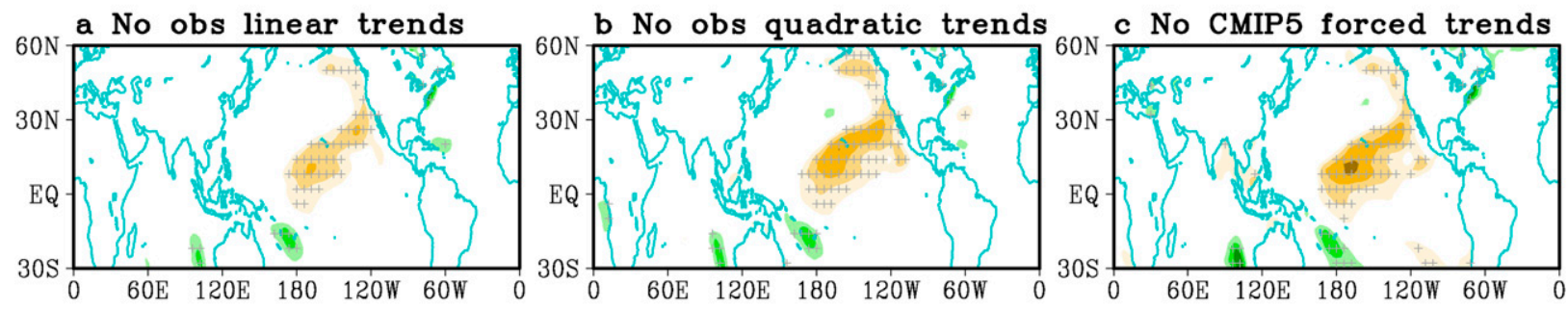

Corr. of Sep sea ice with JJA Precipitation

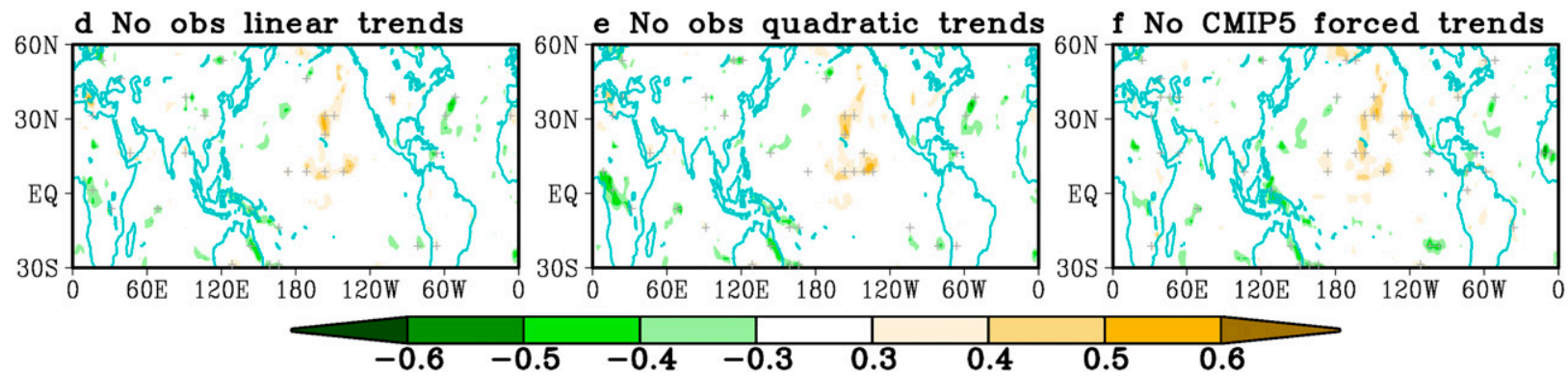

FIG. 4. Correlation map of (a),(d) linearly and (b),(e) quadratically detrended JJA (top) sea surface temperatures and (bottom) GPCP precipitation with September sea ice area from 1979-2017. Correlation map with the (c),(f) ensemble mean CMIP5 forced trends removed from both JJA SST/precipitation and the September total sea ice area index. Stippling indicates statistically significant correlation at the 95\% confidence level (see section $2 \mathrm{f}$ ).

characterized by a strong wavy feature along the jet and near-zero Z200 anomalies in the Arctic.

This global map of Z200, tropical SST, precipitation, and upper-level divergence suggests that the change of September sea ice in the recent decade and its association with JJA Arctic atmospheric conditions (Fig. 1) is partially tied to a shift of the large-scale circulation pattern originating from the tropics, rather than a feature that is confined to the Arctic and extratropics. In particular, the strong melting period from 2007 to 2012 is enhanced by a tropically excited wave train. After 2012, the tropical SST pattern reversed over the ECP. Thus, the momentum originating from the tropics that helped to set up an Arctic circulation pattern conducive to sea ice melt from 2007 to 2012 appears to be absent in recent years.

\section{Tropical-Arctic teleconnection in the past four decades}

\section{a. Correlation between September sea ice and JJA global SST/precipitation}

Further evidence of the tropical-Arctic teleconnection is established by a correlation map between detrended JJA SST/precipitation and September total sea ice area (Fig. 4). Three methods (observed linear and quadratic trends and simulated historical trends derived from the ensemble average of 27 models in CMIP5) are used to remove long-term trends in all SST, precipitation, and sea ice data to assess the sensitivity of results to the use of each trend-fitting method. The detrended data without the observed linear trends show significantly related ( $>95 \%$ confidence level) SSTs over the northeast Pacific along the coast of North America and extending to the ECP. Removal of the observed quadratic trends, considering accelerating trends with time (Dirkson et al. 2017), shows a stronger connection over the same area. Using the ensemble mean of 27 CMIP5 models to estimate and remove long-term trends due to anthropogenic forcing from observed sea ice and SST yields a very similar correlation pattern (Fig. 4c) between detrended September sea ice and JJA SST reaching significant correlation of around $0.5-0.6$ over the ECP. The correlation plots with JJA precipitation are qualitatively consistent with those using SST, showing a patch of positive correlation over the ECP (Figs. 4d-f).

\section{b. MCA analysis between Arctic circulation and tropical SST in JJA}

A more rigorous search of leading tropical-Arctic teleconnections in JJA is performed through MCA between tropical SST and Arctic circulation. Figure 5 shows the leading coupled mode of covariability between detrended (linear fit) JJA Z200 in the Arctic 
a MCA1 Z200 in JJA
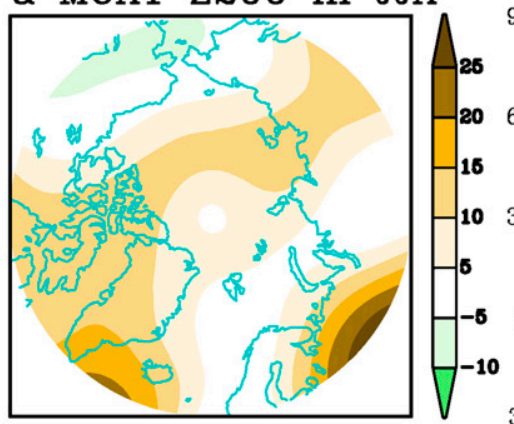

c Sep sea ice

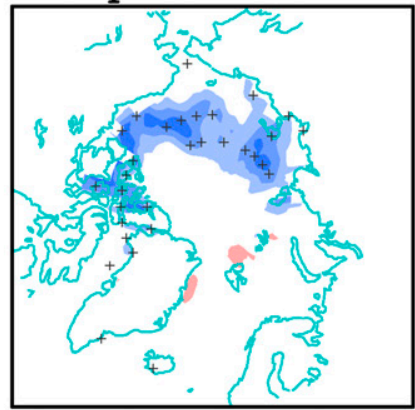

b MCA1 SST in JJA

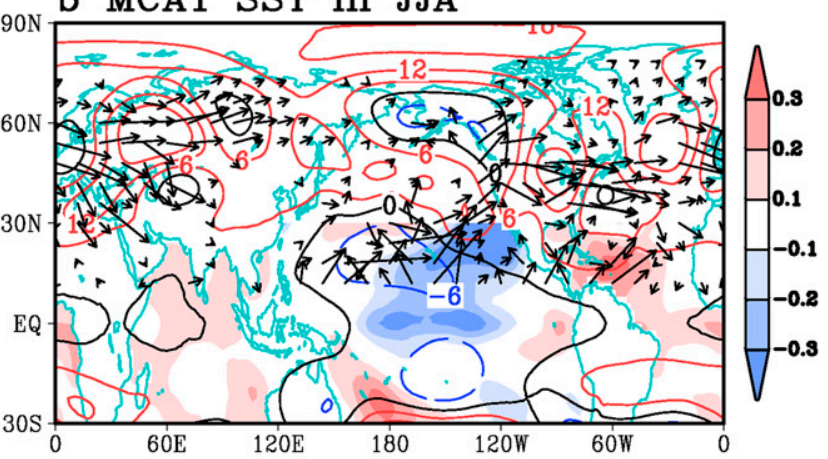

d Z850 and Precipitation in JJA

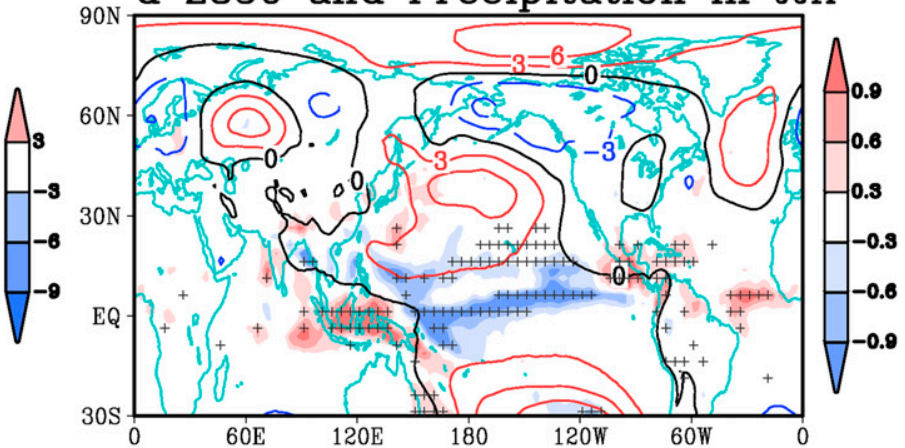

e Time series of MCA1 in JJA and Sep sea ice

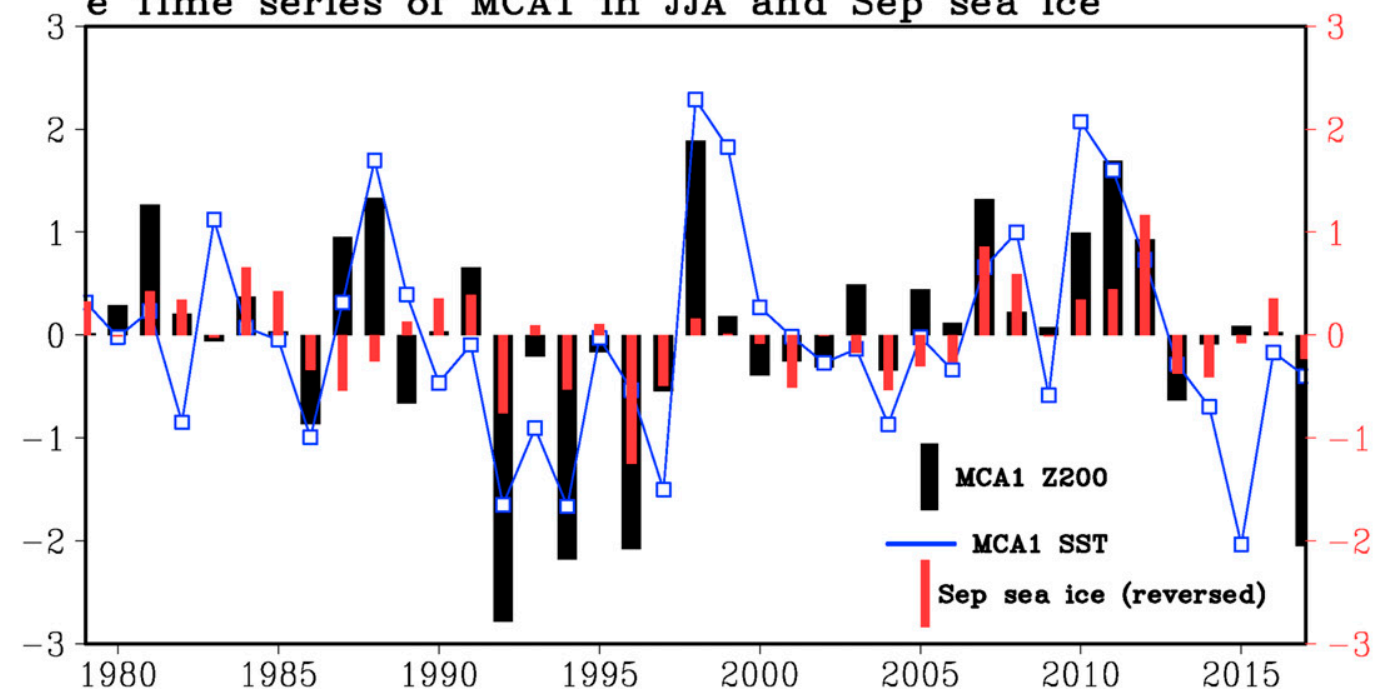

FIG. 5. Leading maximum covariance analysis mode from 1979-2017 between detrended ERA-I (a) JJA 200-hPa geopotential height in the Arctic $\left(60^{\circ}-90^{\circ} \mathrm{N}\right)$ and (b) JJA SST in the tropics $\left(30^{\circ} \mathrm{S}-30^{\circ} \mathrm{N}\right.$, shading) and (e) their corresponding time series. In (b), contours indicate JJA Z200 regressed onto the first SST mode time series. Arrow vectors in (b) represent Plumb wave flux activity associated with the regressed Z200 pattern. The first mode accounts for $48 \%$ of the covariance and the correlation between the time series of the Z200 and SST mode is 0.66 , which is statistically significant at the $95 \%$ confidence level. (c) Regressed September sea ice concentration pattern associated with the leading Z200 mode. (d) Regressed JJA Z850 (contours, unit: m) and precipitation (shading, unit: $\mathrm{mm} \mathrm{day}^{-1}$ ) pattern associated with the leading SST mode. Gray stippling indicates statistically significant regressed (c) sea ice and (d) precipitation values at the 95\% confidence level. (e) Leading MCA1 Z200 (black bars), MCA1 SST (blue line) time series, and total September sea ice area (red bars, sign reversed). We define the PARC as MCA1 shown here. 


\section{trends from 1992 to 2000}

a JJA Z200 trend

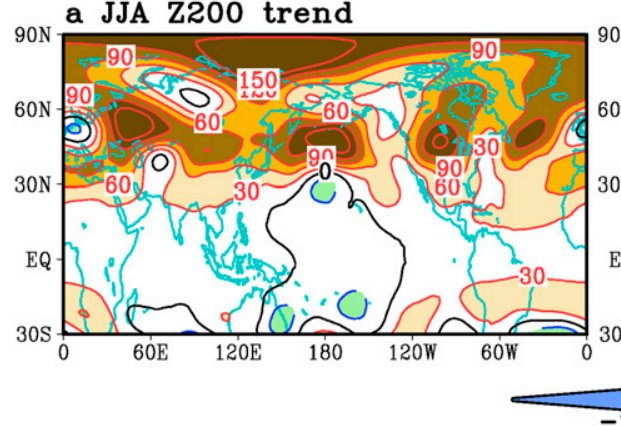

b JJA SST trend

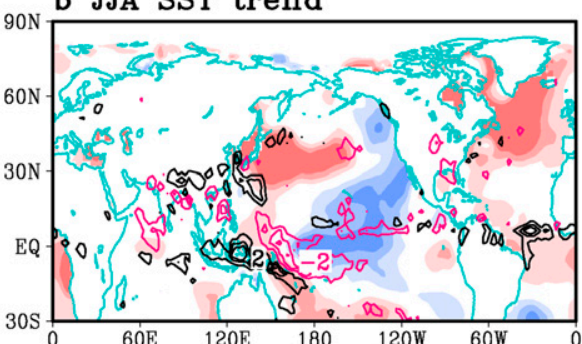

c Height/Temp/Hum

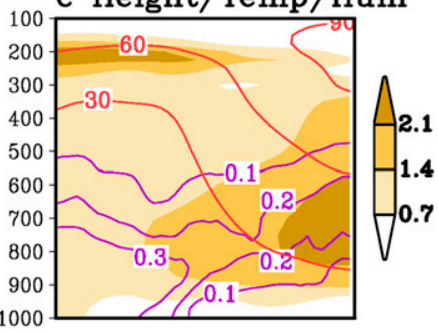

FIG. 6. The linear trend in (a) ERA-I JJA 200-hPa geopotential height (unit: $\mathrm{m} \mathrm{decade}^{-1}$ ) for 1992-2000. The linear trend in (b) ERSST JJA SST (shading, unit: ${ }^{\circ} \mathrm{C}$ decade ${ }^{-1}$ ) and GPCP precipitation (thin contours, unit: $1 \mathrm{~mm}$ decade ${ }^{-1}$ ) for 1992-2000. Black contours indicate positive precipitation trends. The linear trend in (c) ERA-I JJA zonal mean geopotential height (shading, unit: $\mathrm{m}$ decade ${ }^{-1}$ ), temperature (red contours, unit: ${ }^{\circ} \mathrm{C}$ decade ${ }^{-1}$ ), and specific humidity (purple contours, unit: $\mathrm{g} \mathrm{kg}^{-1} \mathrm{decade}^{-1}$ ) for $1992-2000$.

(north of $60^{\circ} \mathrm{N}$ ) and simultaneous tropical SST within $30^{\circ} \mathrm{S}$ and $30^{\circ} \mathrm{N}$. An elongated area of high pressure extending from Greenland to Siberia is closely coupled with a tropical SST pattern consisting of cooling SST and decreased precipitation over the ECP but warming over the rest of the ocean basins. The high pressure over the Arctic is related to Rossby wave train propagation from the Pacific toward Greenland and the Arctic. The Rossby wave energy propagation associated with the wave train appears to originate from the ECP, where a clear baroclinic Gill-type response associated with the SST pattern indicates a significant role of tropical SST cooling and decreased convection over the ECP in driving the Rossby wave train toward the Arctic. Hereafter, this tropical SST-Arctic circulation linkage will be referred to as the Pacific-Arctic (PARC) teleconnection (Fig. 5), and the positive phase of the PARC mode refers to high pressure in the Arctic coupled with an ECP SST cold anomaly. The SST and Z200 patterns forming the leading MCA mode over the 1979-2017 period exhibit a similarity with the anomalous circulation patterns that coincided with the fastest period of sea ice decline during 2007-12 (see Figs. 3c and 3d) and show a pronounced shift around 2013 (Figs. 3e,f). The MCA Z200 time series is correlated with the detrended September sea ice index $(r=0.61$, Fig. 5e), suggesting that the JJA Z200 mode revealed here can indeed lead to subsequent sea ice anomalies in September. The time series of the MCA modes also indicate that a similar PARC teleconnection may have caused another climate shift in the Arctic from 1992 to $\sim 2000$ (Fig. 5e), which can be seen in trends of JJA Z200 and SST during that period (Fig. 6). During those nine years, a quick switch of tropical SST toward a cooling trend over the ECP (Fig. 6b) appears to correspond with an abrupt height rise and atmospheric warming and moistening in the Arctic (Fig. 6c). September sea ice decline also shows a slight intensification during this period relative to the preceding years. However, due to circumstances likely related to the sea ice condition, the response is not as strong as that from 2007 to 2012 (Fig. 1a). A similar MCA using detrended (linear fit) monthly mean fields also shows a similar coupling pattern year-round (Fig. 7). Thus, these MCA results are evidence suggesting changes in the $\mathrm{NH}$ large-scale circulation are in part being driven by SSTs in the tropics and that the PARC mode represents the leading internal teleconnection linking the tropics with the Arctic, in summertime as well as throughout the year.

The SST component of the PARC shows a striking resemblance with the Pacific decadal oscillation (PDO) (Screen and Francis 2016; Screen and Deser 2019) and interdecadal Pacific oscillation (IPO) (Mantua et al. 1997; Henley et al. 2015). A number of recent studies have also found that Arctic sea ice changes have coincided with other primary modes of Pacific decadal variability, but most have focused on winter teleconnections (Screen and Francis 2016; Meehl et al. 2018; Screen and Deser 2019). The spatial pattern of the leading SST mode, obtained here from MCA, reinforces the connection between tropical Pacific SSTs and the Arctic, showing a similar pattern to the PDO and IPO. The PDO and IPO indices also show phase shifts in the late 1990s and early 2010s that coincide with shifts in the time series of the PARC (Fig. 5e). To further illustrate this connection, we find correlations ( $r=0.54$ and 0.63 ) between the time series of our MCA1 SST mode with the detrended PDO index derived from Wills et al. (2018) and the IPO 
a MCA1 Z200

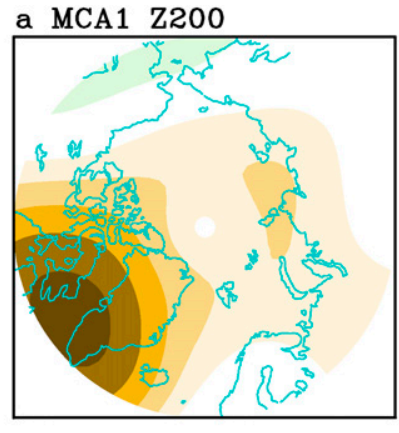

b MCA1 SST

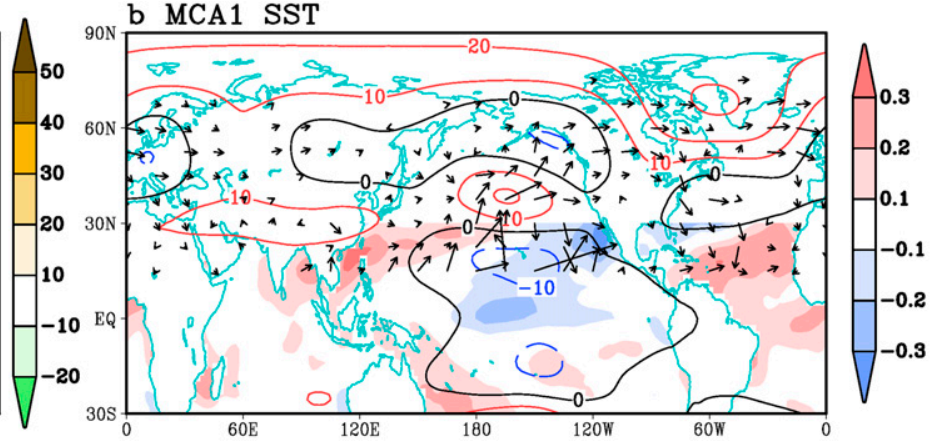

3 c Time series of MCA1

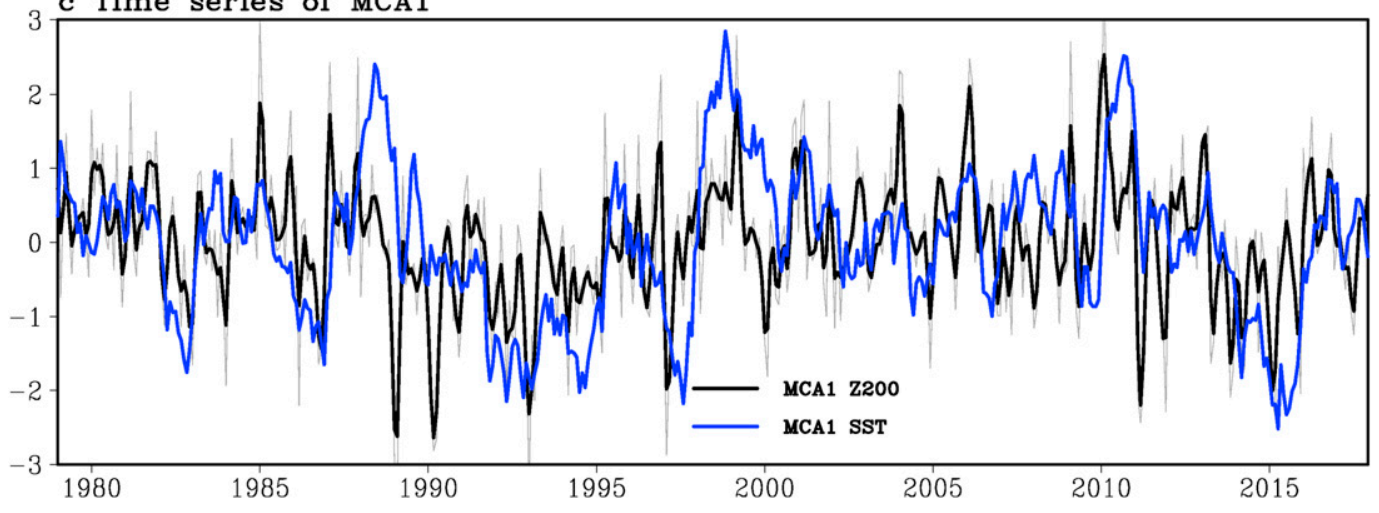

FIG. 7. As in Fig. 5, but showing detrended monthly (a) $200-\mathrm{hPa}$ geopotential height in the Arctic $\left(60^{\circ}-90^{\circ} \mathrm{N}\right.$, shading) and (b) tropical SST (30 S $-30^{\circ} \mathrm{N}$, shading) from 1979-2017 and (c) their corresponding time series. Also shown in (b) are the spatial projections for monthly Z200 regressed onto the first SST mode time series (contour). Arrow vectors in (b) represent Plumb wave flux activity associated with the regressed Z200 pattern. The climatological annual cycles and linear trends are removed first from the two fields before the MCA calculation. The first mode accounts for $58 \%$ of the covariance and the correlation between the time series of the Z200 and SST mode is 0.36 , which is statistically significant at the $5 \%$ confidence level considering that the effective sample size [based on Eq. (1)] is around 200 monthly values. In (c), the dark black curve is a three-month running mean of the monthly time series of MCA1-Z200 (gray).

index constructed by NOAA/ESRL (Henley et al. 2015). The high correlation between these two modes and the PARC is primarily the result of their overlapping SST domains in the ECP, where the strongest correlation between SST and Arctic sea ice is found (Fig. 4). While variability in these modes clearly maps onto the proposed mechanism, we suggest that through the use of the PARC, which by definition focuses on the teleconnection between Pacific SSTs and Arctic sea ice, a better understanding of the key processes driving tropical-Arctic teleconnections can be achieved.

\section{Simulated circulation responses to tropical SST change from 2007 to 2012 in the pacemaker experiment}

Through our observational analysis, we find that the abrupt melting from 2007 to 2012 , associated with a shift to high pressure over the Arctic driven by tropical ECP
SST anomalies, is likely a contributor to the appearance of a slowdown in the sea ice decline over the past 10 years. To establish the causal connection from tropical ECP SST to the Arctic circulation anomaly, we examine the difference between 2007-12 and 1979-2017 pacemaker experiments (Fig. 8b). Forcing the model with observed tropical ECP SST generates a northeastward propagating Rossby wave train with high pressure in the Arctic (Fig. 8b). This pattern is similar (pattern correlation of 0.44 within the Arctic) to the observed PARC teleconnection (Fig. 8a) and suggests that ECP SST plays an important role in generating the observed PARC teleconnection from 2007 to 2012. However, the simulated height increase in the Arctic $\left(70^{\circ}\right.$ to $\left.90^{\circ} \mathrm{N}\right)$ shows a weaker magnitude $(\sim 12 \mathrm{~m})$ and a somewhat different pattern than the observed pattern $(\sim 31 \mathrm{~m})$, indicating model limitations and contributions from other factors that are not fully accounted for in our experiments. Though weak, the model does well to capture the observed zonal mean tropospheric structure, 
a) Observed JJA Z200 and rain (07-12 minus 79-17)

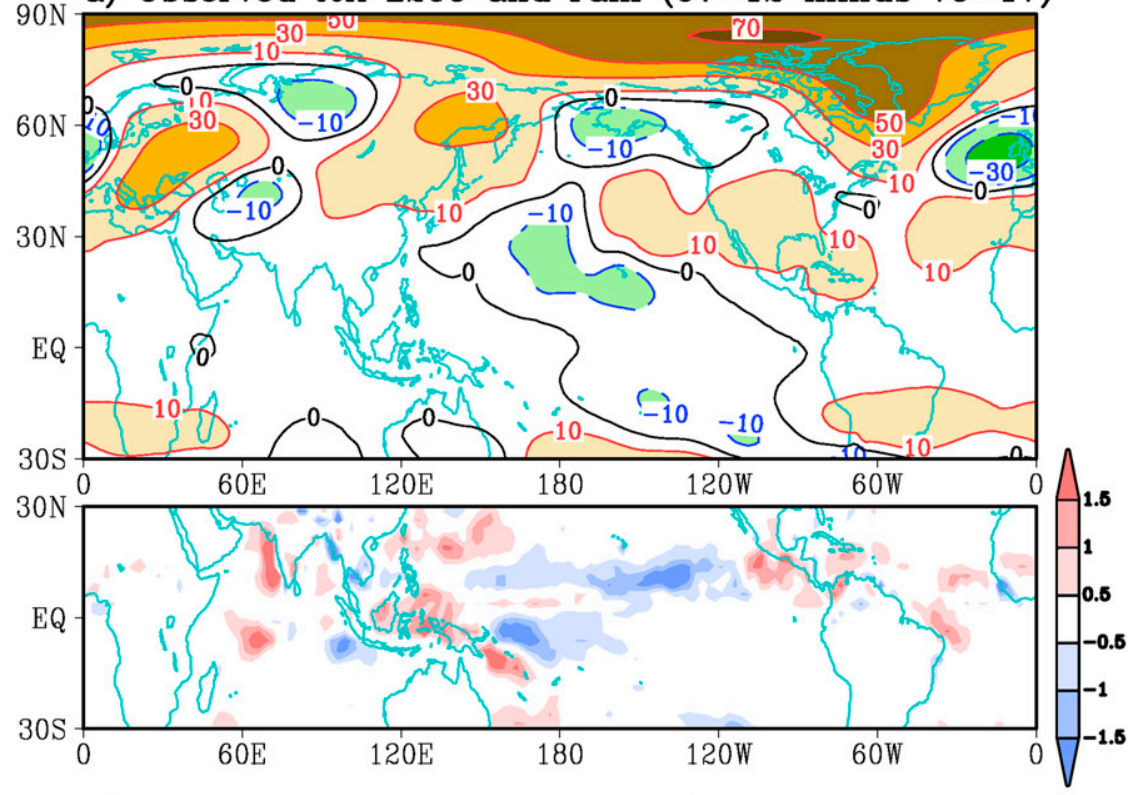

b) Simulated JJA Z200 and rain (07-12 minus 79-17)

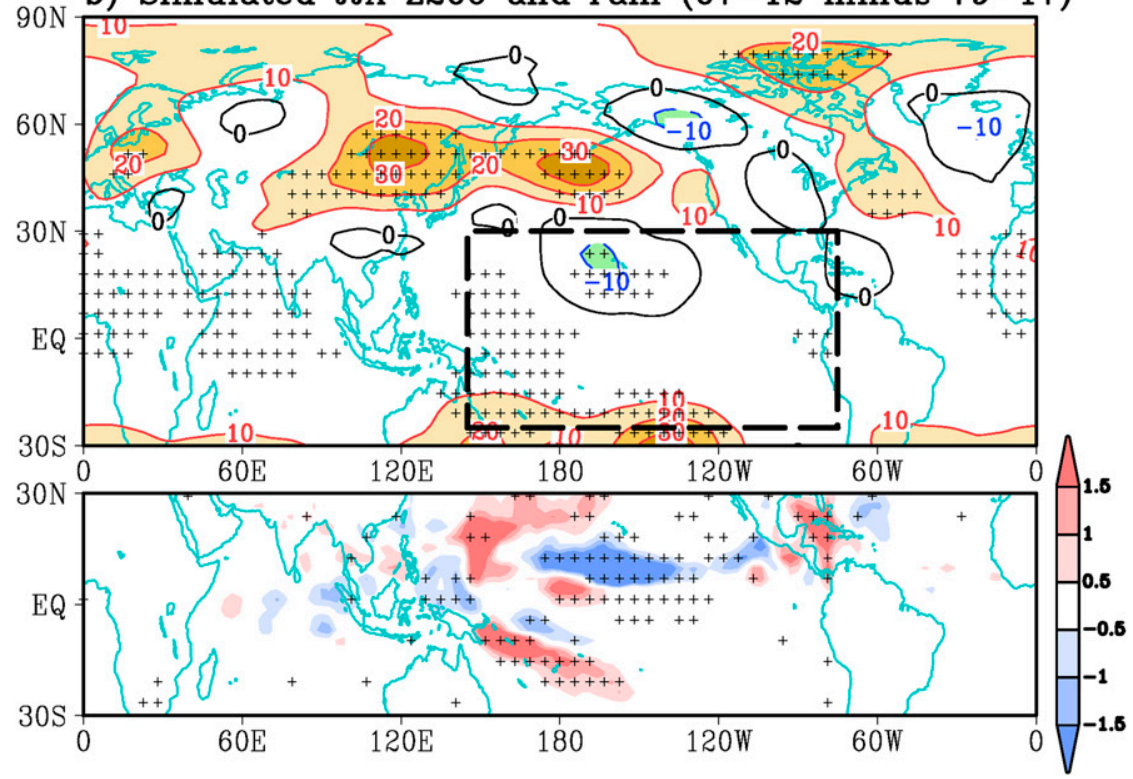

FIG. 8. (a) (top) Observed JJA 200-hPa geopotential height (unit: m) and (bottom) precipitation anomalies (unit: $\mathrm{mm} \mathrm{day}^{-1}$ ) for 2007-12 minus the 1979-2017 long-term average. (b) As in (a), but for JJA 200-hPa geopotential height and precipitation response from the pacemaker experiment (2007-12 vs 1979-2017). The difference is calculated as the 30-yr average of the two experiments (2007-12 minus $1979-2017)$. The dashed black box $\left(25^{\circ} \mathrm{S}-30^{\circ} \mathrm{N}\right.$, $145^{\circ}-285^{\circ} \mathrm{E}$ ) indicates the region where observed SSTs were prescribed to force the model. Stippling in (b) indicates statistically significant differences at the $95 \%$ confidence level by the two-sample Student's $t$ test.

with a barotropic geopotential height rise and near-surface warming and moistening centered over the Arctic (Fig. 9 vs Fig. 1). The commonalities and differences are best illustrated using a polar projection (Fig. 9) that shows that the model generates a center of an upper-level height rise that is comparably placed with observations but does not fully replicate the very large increase seen from 2007 to 2012 and its extension into the Arctic. The ensemble mean of the sea ice response from our pacemaker experiment is also weaker at about $30 \% \sim 40 \%$ of 
a Obs Z200

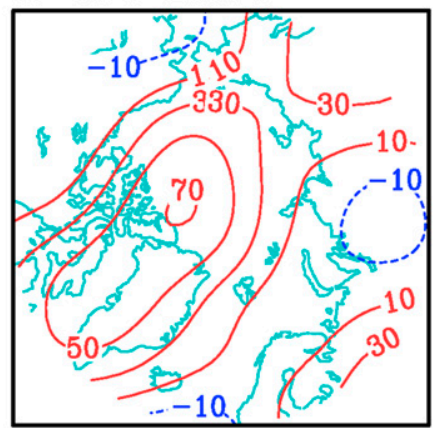

b $\mathrm{Z} 200$ in model

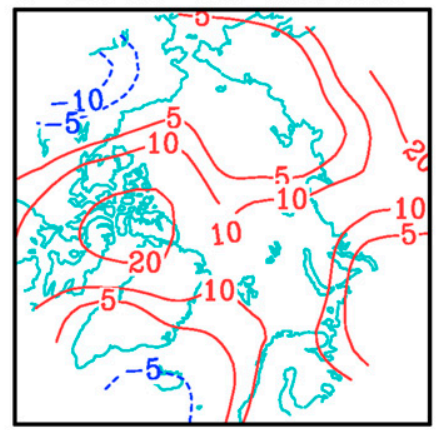

\section{c Spreads}

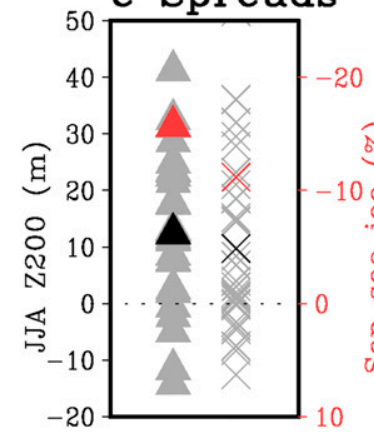

d PDF of JJA Z200 response

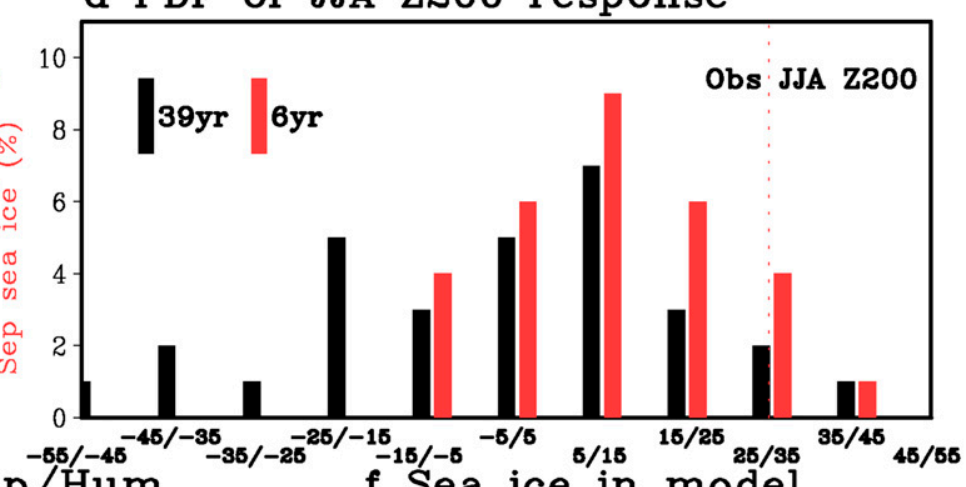

e Height/Temp/Hum

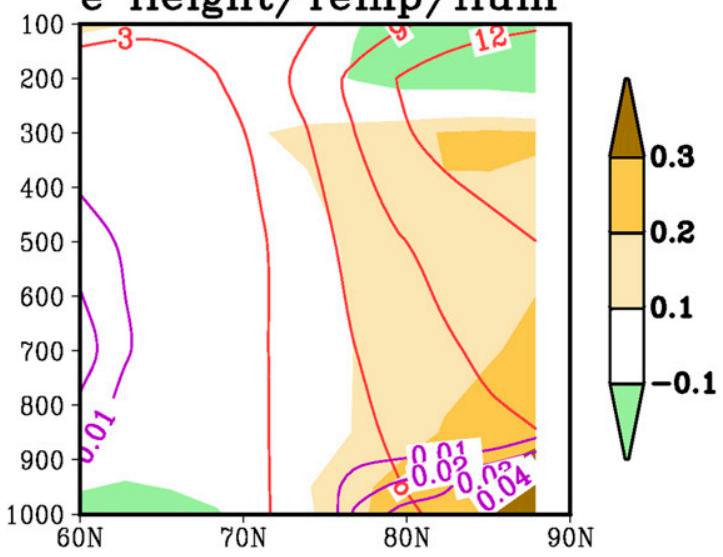

f Sea ice in model

FIG. 9. (a) Observed Z200 anomalies from 2007 to 2012 (same as in Fig. 1). (b) As in Fig. 8b, showing JJA 200-hPa geopotential height response from the experiment (2007-12 vs 1979-2017). The difference is calculated as the 30-yr average of the two experiments (2007-12 minus 1979-2017). (c) JJA Z200 and September sea ice anomalies (minus 30-yr average of $1979-2017$ run $)$ averaged within the Arctic $\left(70^{\circ}-90^{\circ} \mathrm{N}\right)$ from each year $(\mathrm{Z} 200$ : gray triangle; sea ice: gray cross) in 2007-12 run. The black and red triangles/crosses denote the 30-yr average in the 2007-12 run and observed value in ERA-I/NSIDC, respectively. (d) The probability density function (PDF) of 30-yr JJA Z200 responses (minus 30-yr average of 1979-2017 run) in the Arctic $\left(70^{\circ}-90^{\circ} \mathrm{N}\right)$ in $2007-12$ and $1979-2017$ runs. The numbers along the $x$ axis indicate the intervals of the PDF. For example, $-5 / 5$ indicates the bin with JJA Z200 response varying between -5 and $5 \mathrm{~m}$. The observed JJA Z200 anomaly (2007-12 minus 1979-2017) is denoted by the dashed red line over the interval between 25 and $35 \mathrm{~m}$. (e) Zonal mean latitude-vertical profile of difference in geopotential height (red contours, $\mathrm{m}$ ), temperature (shading, unit: ${ }^{\circ} \mathrm{C}$ ), and specific humidity (purple contours, unit: $\mathrm{kg} \mathrm{kg}^{-1}$ ) between the two experiments (2007-12 minus 1979-2017). (f) September sea ice concentration response (unit: \%) from the experiments (2007-12 minus 1979-2017). 


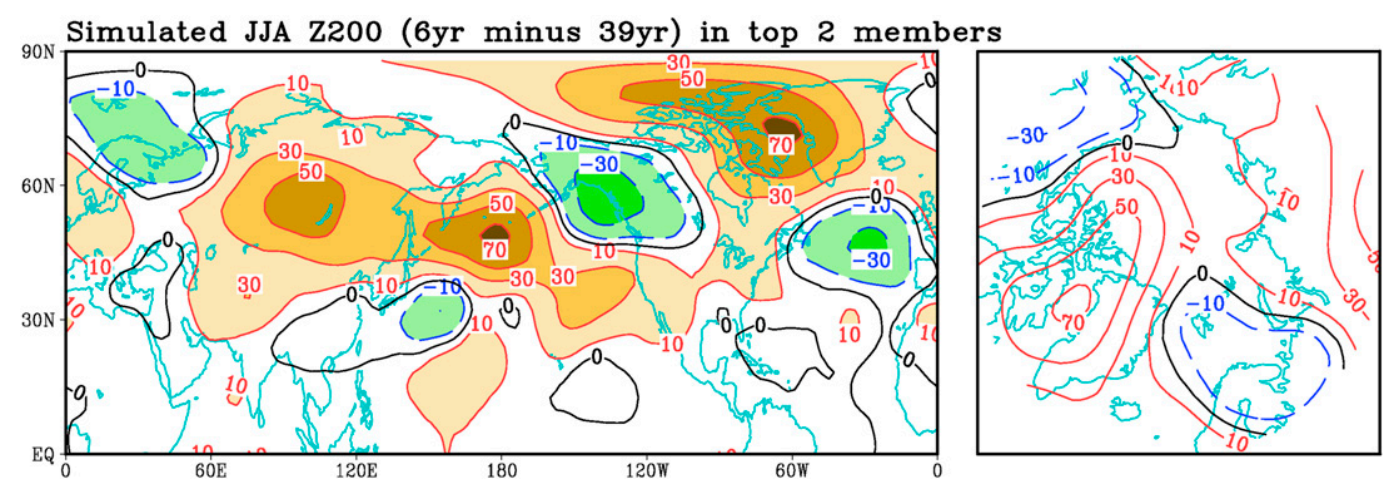

FIG. 10. Simulated Z200 height response (2007-12 minus 1979-2017, unit: m) from the two members in the pacemaker experiment with the strongest Arctic-averaged Z200 $\left(70^{\circ}-90^{\circ} \mathrm{N}\right)$.

the observed response. A possible explanation for the weaker than observed sea ice response is that, because we couple ECHAM4.6 with a slab ocean model, our experiment only reflects the sea ice response to thermodynamic effects of the overlaying atmosphere, though thermodynamic and dynamic (wind) forcing tend to contribute in roughly equal parts to Arctic sea ice variability (Fig. 9f). It should also be noted that the use of a slab ocean model, which does not account for dynamic ocean heat transport as would a fully dynamic ocean model, could also be playing a role in the weak pacemaker response to tropical forcing. However, an examination of the ensemble spread (Fig. 9c) shows that some ensemble members have JJA Z200 and September sea ice response magnitudes as large as observed and feature a strong pattern resemblance with observed Z200 anomalies over the 2007-12 period. The distribution of these Arctic-averaged height values is Gaussian in both the control and forced simulations (Fig. 9d), but the tropical Pacific SST-driven distribution is shifted toward high geopotential heights in the Arctic. Almost double the number of cases with the higher geopotential heights and few cases with negative values suggests a cooler ECP favors enhanced Arctic warming. Taking the two members from the tropical SST-forced simulation with Arctic geopotential height rise greater than observed provides a pattern that closely matches the observations (Fig. 10). Thus the very large observed height rise during the 2007-12 event was likely a case in which tropical forcing was superimposed onto other internally driven factors.

One factor possibly playing an important role in the prominence of the observed PARC pattern in our experiment is the Arctic Oscillation (AO), which was negative for several summers from 2007 to 2012 (L'Heureux et al. 2010). It is known that the AO or NAO is the leading internal circulation mode in the Arctic, and it is sensitive to remote tropical forcing
(Hoerling et al. 2001; Ding et al. 2014; Trenberth et al. 2014). However, models have trouble simulating the correct relationship between the $\mathrm{AO}$ and tropical forcing (L'Heureux et al. 2008; Ding et al. 2019). A recent study (Liu et al. 2018) further suggests that the circulation pattern that is optimal for Arctic warming, such as a negative AO phase, could own an origin from an intrinsic mode excitation in the high latitudes, tending to be efficiently forced by an oceanic flux in the eastern equatorial Pacific. It is very likely that the relationship between the AO and tropical forcing is not well captured in the pacemaker experiments and may be an additional cause of some of the discrepancies between our experiment and observations. Nevertheless, the driving mechanism for this teleconnection, a wave train propagating from the ECP to the Arctic with a high pressure center over Greenland, is replicated in our simulation. To investigate the sensitivity of the ECP region in our pacemaker experiment, we conduct several additional experiments, extending the SST pacemaker domain to the entire tropics $\left(30^{\circ} \mathrm{S}\right.$ to $\left.30^{\circ} \mathrm{N}\right)$ or the whole Pacific from $30^{\circ} \mathrm{S}$ to $60^{\circ} \mathrm{N}$. The simulations of $\mathrm{Z} 200$ anomalies during 2007-12 in the Arctic are not significantly changed compared to the simulation only forced by SST in the ECP. This result suggests that SST changes in the ECP have a stronger effect on Arctic circulation changes relative to the rest of the tropics and that the ECP is uniquely capable of driving the Pacific-Arctic teleconnections.

\section{A tropical-driven teleconnection favoring extreme sea ice melting in a long preindustrial simulation}

Because we only use a slab-type thermodynamic ocean and sea ice model in our pacemaker experiment, a fully coupled model with a capability to resolve dynamic 
a Time sereis of $6-y r$ mean September sea ice area

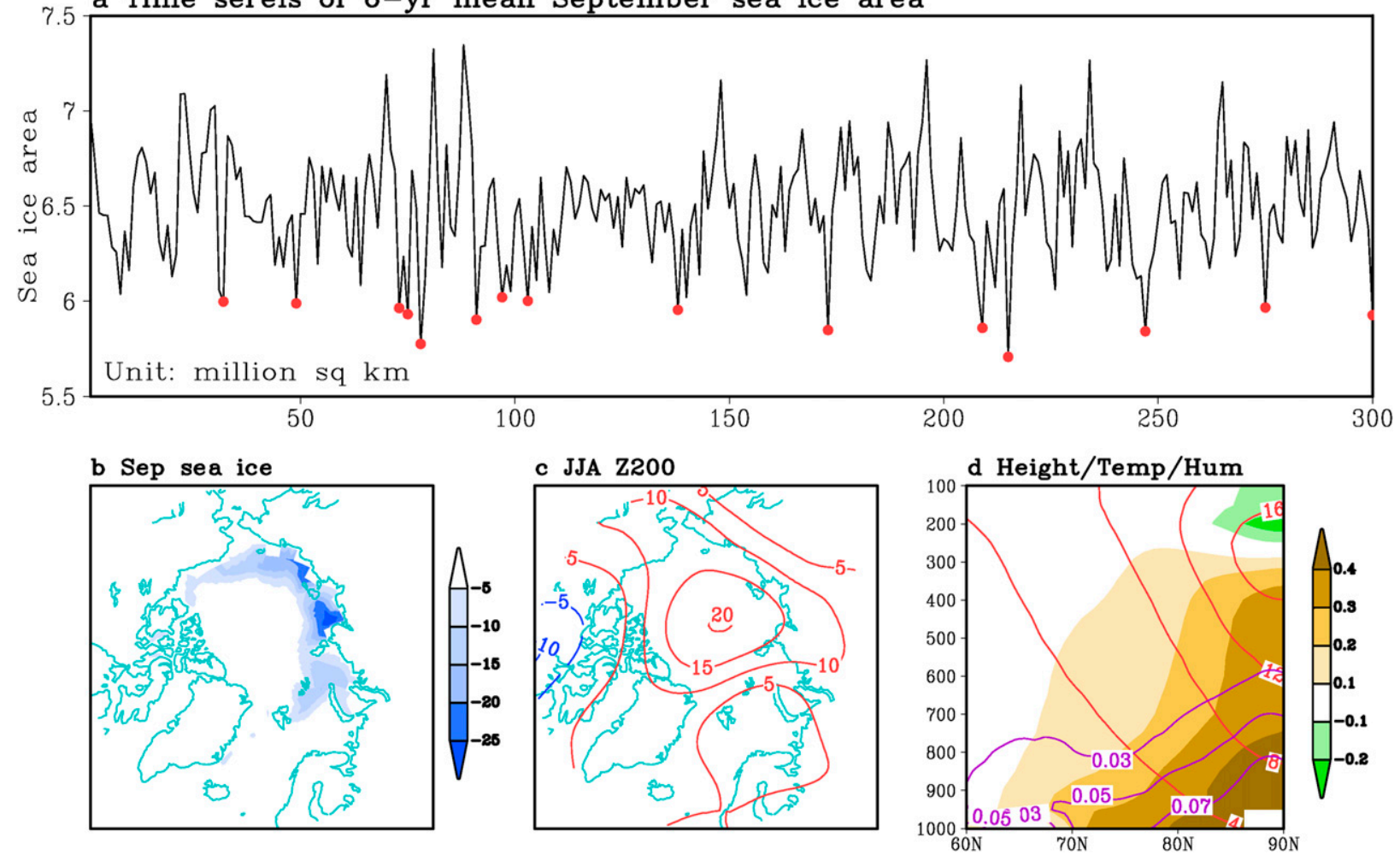

FIG. 11. (a) 300 nonoverlapping 6-yr means of total September sea ice area from the 1800-yr CESM preindustrial control run. Red dots denote the 15 periods with the lowest 6-yr mean total September sea ice area, identified using a 95th-percentile threshold. (bottom) Corresponding (b) September sea ice concentration anomalies (blue shading, unit: \%), (c) Z200 anomalies (red contour, unit: m), and (d) zonal mean latitude-vertical profile of geopotential height (red contour, unit: $\mathrm{m}$ ), temperature (shading: ${ }^{\circ} \mathrm{C}$ ), and specific humidity (purple contour, unit: $\mathrm{g} \mathrm{kg}^{-1}$ ) relative to the 300 -period mean. All plotted values from (b) to (d) are significant at the $95 \%$ confidence level based on the one-sample $t$ test.

and thermodynamic responses of ocean and sea ice to atmospheric variability is needed to further explore the sensitivity of Arctic sea ice to local and remote atmospheric forcing. Thus, we make use of the CESM's preindustrial simulation to examine dominant atmospheric circulation patterns favoring enhanced sea ice melting. The main purpose of this examination is to identify the typical local and global circulation patterns that are associated with significant sea ice melting periods in this long simulation and to further explore whether such circulation patterns own a tropical origin and share a similarity with the PARC in observations. Since anthropogenic forcing is not specified in this experiment, sea ice variability is only driven by the model's internal variability.

To find analogs to the 2007-12 period of accelerated sea ice loss in this long-term simulation, we use a similar "fast minus slow" composite approach to that from Ding et al. (2019), but rather than examining the spread, we focus only on the fast melting group. We partition the 1800-yr CESM preindustrial simulation into a pseudoensemble of 300 nonoverlapping 6-yr periods and calculate the total September sea ice area (Fig. 11a). Six-year mean September sea ice area in the long preindustrial simulation exhibits a long-term average around 6.5 million $\mathrm{km}^{2}$, which is similar in magnitude to the observed values during the early $1980 \mathrm{~s}$ $\left(\sim 5.9\right.$ million $\left.\mathrm{km}^{2}\right)$. We use the 95 th percentile as a threshold to select the 15 episodes with the lowest total September sea ice area. The mean of these 15 low ice periods is -0.59 million $\mathrm{km}^{2}$ below the long-term average, closely matching the observed 2007-12 anomalies calculated from the detrended anomalies in Fig. 2 $\left(-0.57\right.$ million $\left.\mathrm{km}^{2}\right)$. This makes the ensemble of the 15 low ice periods a reasonable simulated analog for the observed fast melting period from 2007 to 2012 . The composite patterns of September sea ice anomalies associated with the 15 lowest sea ice episodes (Fig. 11b) show a strong resemblance to the observed pattern from 2007 to 2012, though the anomaly is shifted from the Beaufort-Chukchi sector toward the Laptev Sea. We then obtain the composites of JJA 


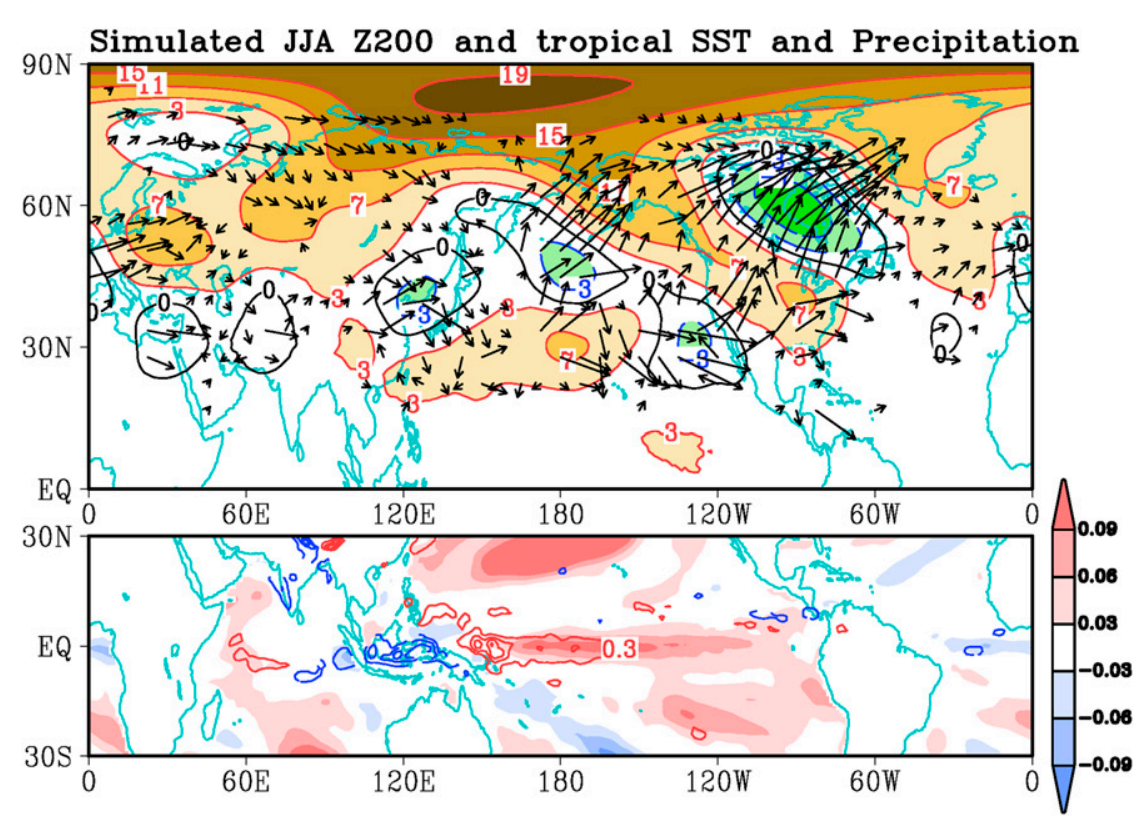

FIG. 12. (top) Z200 (contours and shading, unit: m) and Plumb wave activity flux (vectors) from the 15 lowest 6-yr sea ice area periods in the CESM preindustrial control run. The 15 periods are shown in Fig. 11a. (bottom) Sea surface temperature (shading, unit: ${ }^{\circ} \mathrm{C}$ ) and precipitation (red/blue contour, unit: $0.3 \mathrm{~mm}$ per day) from the same 15 periods as the top panel. All plotted values are significant at the $95 \%$ confidence level based on the one-sample $t$ test.

Z200 and zonal mean geopotential height, temperature, and specific humidity based on the 15 cases, revealing the internal local Arctic atmospheric patterns most favorable for enhanced September sea ice loss (Fig. 11). Within the Arctic, the composite patterns show a barotropic high pressure structure, consistent with the observations and pacemaker experiment, characterized by increased geopotential heights centered between 200 and $400 \mathrm{hPa}$ over the pole and warming and moistening near the surface. However, just like in the pacemaker experiment, the composite pattern has a weaker than observed upper-level height rise over the Arctic $(\sim 12-16 \mathrm{~m})$.

In the global composite map of Z200, SST and precipitation (Fig. 12), a wave train originating from the tropical Pacific is clearly present. Rossby wave energy inducing the barotropic high pressure in the Arctic appears to primarily propagate into the Arctic through the Pacific sector. In the tropics, a narrow band of warm SST and related enhanced precipitation are observed along the equator across the entire Pacific. This warm SST anomaly seems to be the key source driving the teleconnection emanating from the tropical-extratropical North Pacific toward the Arctic. This analysis confirms our findings in the observational analysis and pacemaker run that tropical SST forcing in the Pacific is essential to excite a poleward propagating Rossby wave train and barotropic high pressure in the Arctic that further favors strong sea ice melting. However, it should be noted that the phase of the simulated tropical-Arctic connection in the CESM is opposite to that associated with the observed PARC and that in the pacemaker experiment. In addition, Rossby wave energy in the CESM, originating from the tropical Pacific, primarily enters the Arctic through the Pacific sector, rather than near Greenland. It is unclear to what extent these differences can be attributed to the use of a slab ocean model as opposed to a fully coupled model or the use of ECHAM as opposed to CAM. Going forward, further intermodel comparison and hierarchy experiments, focusing on the PARC, may be needed to tease apart the relative contributions of these factors. Despite these discrepancies in the simulated teleconnection patterns in the CESM, this result reinforces the idea that tropical Pacific SST forcing can act as an internal source of variability contributing to accelerated September sea ice loss via Rossby wave propagation from the Pacific to the Arctic and the observed PARC could be generated and maintained through similar Rossby wave dynamics.

\section{Conclusions and discussion}

In this paper, we show observational evidence, supported by modeling experiments, that a recent shift in tropical Pacific SST, driving a PARC teleconnection propagating into the $\mathrm{NH}$ high latitudes, is partially 
responsible for a strong melting period from 2007 to 2012. From 1979 to the early 2000s, the tropical SST pattern features a warming trend everywhere except over the ECP, accompanied with a circumglobal teleconnection pattern along the jet. During 2007 to 2012, the aforementioned SST pattern became even stronger, resulting in an enhanced PARC teleconnection with accelerated Arctic warming and sea ice melting. From 2013 to 2017, the SST pattern flips sign over the ECP, weakening the PARC circulation contribution to the Arctic warming and sea ice melting. These changes originating in the tropics seem to be capable of modulating $\mathrm{CO}_{2}$-driven atmospheric warming and sea ice melting by strengthening the anthropogenic signal from 2007 to 2012. The slowdown in September sea ice loss from 2007 to 2017 is likely in part due to a transition from a situation in which the tropics reinforced anthropogenic forcing to a return to the long-term trend associated with anthropogenic forcing.

It remains unclear how this tropical SST mode, which helps to determine the rate of sea ice loss, will evolve in the future. The persistence of the current slowdown in the September sea ice area trend is highly dependent on future changes in tropical SST along with the continuation of anthropogenic climate change. Interdecadal tropical SST variability in the future is therefore a prominent source of uncertainty in projections of Arctic sea ice and climate. Another source of model uncertainty arises from model limitations in capturing the PARC teleconnection in summer. For example, the observed tropical-Arctic relationship, between a cold (warm) ECP, warm (cold) Arctic, and fast (slow) sea ice decline is opposite to that simulated by the CESM (Ding et al. 2019, their Figs. 11 and 12). In the CESM, an IPO-like internal tropical SST change featuring an ECP warming trend is suggested to favor accelerating sea ice melting, contributing to melting from anthropogenic forcing, in the coming decades (Screen and Deser 2019). However, this scenario is not consistent with what we have found in observations: an ECP SST change toward a warming phase of the IPO after 2012 is associated with a slowdown of sea ice loss. This conflict is likely due to the opposite phase relationship of the PARC-like mode in observations relative to the CESM (Fig. 12). Another possibility is differences in the time scales investigated by Screen and Deser (2019), who examine 20+-yr trajectories, while the reversal from the PARC-driven accelerated melting in the observational record is only 7 years long. Variation of the PARC mode across other models needs to be examined in future research.

In our view, this limitation of the CESM in replicating the PARC is possibly due to the nature of the PARC's formation, which is summarized in Fig. 13 and based on

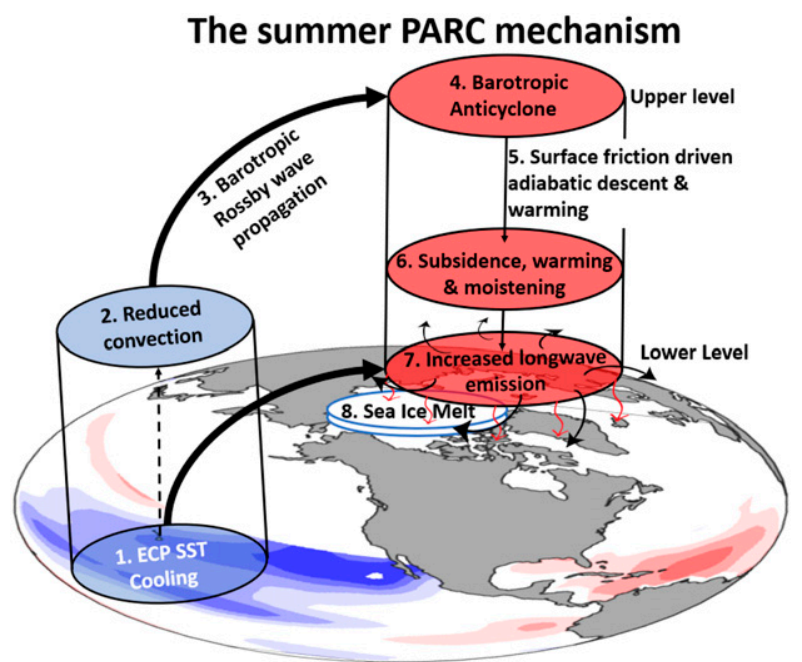

FIG. 13. A schematic diagram summarizing the formation mechanism of the PARC. Shading shows the leading SST mode derived from MCA (derived from Fig. 5b), exhibiting a SST cooling over the ECP. The formation of the positive phase of the PARC could be understood as an integrated process originating from the tropics: 1) cool SST anomalies in the eastern-central Pacific lead to 2) reduced local convection; reduced convection generates anomalous upper-level divergence, that further creates 3) barotropic Rossby wave train propagation along a great circle path from the tropical Pacific to the Arctic, favoring a 4) barotropic anticyclone centered over northeastern Canada and Greenland and extending into the Arctic over the sea ice; 5) at the surface, friction causes anticyclonic winds (denoted as black thin arrows in the Arctic) to diverge outward, leading to downward movement of air to conserve mass; 6) as the air descends, it adiabatically warms, allowing for it to hold more moisture and 7) the combination of warming and moistening leads to increased emission of longwave radiation (denoted as thin red arrows above sea ice). 8) Melting of sea ice is primarily driven by this emission of longwave radiation resulting from a combination of warming and moistening of the lower Arctic atmosphere through the generation of the PARC.

this work and several previous studies (Ding et al. 2017, 2019; Wernli and Papritz 2018; Meehl et al. 2018; Screen and Deser 2019). Changes in convection originating from IPO- or PDO-like variations in Pacific SST force Rossby wave propagation from the tropics to the Arctic. This connection is particularly prominent from 2007 to 2012, as cold SST anomalies in the ECP can generate decreases in tropical convection and upper-level divergence, resulting in a wave train structure with a barotropic high pressure system over northeast Canada and Greenland that extends into the Arctic. Friction near the surface creates ageostrophic winds that, in the case of anticyclonic motion, diverge outward and create increased large-scale subsidence in the lower troposphere. As the air descends it adiabatically warms and thus emits more longwave radiation that contributes to enhanced sea ice melting. The warmer air also holds 
more moisture, favoring an additional source of increased downwelling clear-sky longwave radiation to further melt sea ice. The cloud radiative response to the summertime PARC is less certain, but a decrease in cloud cover resulting from large-scale subsidence likely increases downwelling shortwave radiation and can modulate downwelling longwave radiation depending on low cloud changes.

To replicate this chain of physical mechanisms establishing the PARC requires that all individual components be realistically simulated, posing a great challenge to the modeling community (Ding et al. 2019). Considering these limitations and challenges, our experiment (Fig. 8), with observed SST specified in the ECP and a simple ocean and sea ice model used everywhere else, only represents a qualitative test of the PARC mechanism. On the other hand, the CESM long preindustrial simulation shows that tropical Pacific forcing is critical in determining Arctic sea ice variability through a Rossby wave train, though the CESM demonstrates a different phase relationship than the observed tropical SST cooling coinciding with Arctic warming (Fig. 12). Future modeling studies with improved models that own a better skill to replicate the observed tropicalArctic connection are necessary to more quantitatively understand the linkage from Pacific SST to Arctic sea ice and its related mechanisms. It is also suggested that ECP SST changes are sensitive to SST variability over other ocean basins (Vimont et al. 2003; Cai et al. 2019) and may be subject to feedbacks associated with sea ice melting in winter (Deser et al. 2016; Cvijanovic et al. 2017; Sun et al. 2018). Thus, the PARC mode proposed here only illustrates a direct tropical-Arctic linkage in summertime.

In addition, we cannot rule out the possibility that the recent slow rate of sea ice decline may in part be due to a stabilizing feedback of the Arctic climate system. Such a stabilizing feedback is suggested to cause a 2-yr recovery of sea ice after an imposed strong sea ice anomaly (Tietsche et al. 2011). Further efforts are necessary to tease apart the stabilizing effects on the recent slowdown from the tropically forced PARC mechanism.

Acknowledgments. This study was supported by NSF's Polar Programs (OPP1744598, ARC1203425, and OPP-1744587), NOAA's Climate Program Office, Climate Variability and Predictability Program (NA15OAR4310162) and Ocean Observing and Monitoring Division (NA18OAR4310424), and NASA Grant NNX17AD27G. JL was supported by the U.S. Department of Energy Office of Science Biological and Environmental Research (BER) as part of the Regional and Global Climate Modeling
Program. We acknowledge the CESM Large Ensemble Community Project, the Max Planck Institute for Meteorology Grand Ensemble project, and supercomputing resources provided by NSF/CISL/Yellowstone. We thank Dr. Gabor Drotos for discussion. We appreciate the insightful comments and suggestions from the three anonymous reviewers and the editor, James Screen.

\section{REFERENCES}

Bevis, M., and Coauthors, 2019: Accelerating changes in ice mass within Greenland, and the ice sheet's sensitivity to atmospheric forcing. Proc. Natl. Acad. Sci. USA, 6, 116, https:// doi.org/10.1073/PNAS.1806562116.

Bintanja, R., R. G. Graversen, and W. Hazeleger, 2011: Arctic winter warming amplified by the thermal inversion and consequent low infrared cooling to space. Nat. Geosci., 4, 758-761, https://doi.org/10.1038/ngeo1285.

Bretherton, C. S., C. Smith, and J. M. Wallace, 1992: An intercomparison of methods for finding coupled patterns in climate data. J. Climate, 5, 541-560, https://doi.org/10.1175/ 1520-0442(1992)005<0541:AIOMFF >2.0.CO;2.

_ - M. Widmann, V. P. Dymnikov, J. M. Wallace, and I. Bladé, 1999: The effective number of spatial degrees of freedom of a time-varying field. J. Climate, 12, 1990-2009, https://doi.org/ 10.1175/1520-0442(1999)012<1990:TENOSD>2.0.CO;2.

Cai, W., and Coauthors, 2019: Pantropical climate interactions. Science, 363, eaav4236, https://doi.org/10.1126/science.aav4236.

Cavalieri, D. J., C. L. Parkinson, P. Gloersen, and H. J. Zwally, 1996: Sea ice concentrations from Nimbus-7 SMMR and DMSP SSM/I-SSMIS passive microwave data, version 1. Subset used: V3-NH, NASA National Snow and Ice Data Center Distributed Active Archive Center, accessed 29 April 2018, https://doi.org/10.5067/8GQ8LZQVL0VL.

Cohen, J., and Coauthors, 2014: Recent Arctic amplification and extreme mid-latitude weather. Nat. Geosci., 7, 627-637, https:// doi.org/10.1038/ngeo2234.

Coumou, D., G. Di Capua, S. Vavrus, L. Wang, and S. Wang, 2018: The influence of Arctic amplification on mid-latitude summer circulation. Nat. Commun., 9, 2959, https://doi.org/10.1038/ s41467-018-05256-8.

Cvijanovic, I., B. D. Santer, C. Bonfils, D. D. Lucas, J. C. Chiang, and S. Zimmerman, 2017: Future loss of Arctic sea-ice cover could drive a substantial decrease in California's rainfall. Nat. Commun., 8, 1947, https://doi.org/10.1038/s41467-017-01907-4.

Day, J. J., J. C. Hargreaves, J. D. Annan, and A. Abe-Ouchi, 2012: Sources of multi-decadal variability in Arctic sea ice extent. Environ. Res. Lett., 7, 034011, https://doi.org/10.1088/17489326/7/3/034011.

Dee, D. P., and Coauthors, 2011: The ERA-Interim reanalysis: Configuration and performance of the data assimilation system. Quart. J. Roy. Meteor. Soc., 137, 553-597, https://doi.org/ 10.1002/qj.828.

Deser, C., L. Sun, R. A. Tomas, and J. Screen, 2016: Does ocean coupling matter for the northern extratropical response to projected Arctic sea ice loss? Geophys. Res. Lett., 43, 21492157, https://doi.org/10.1002/2016GL067792.

Ding, Q., J. M. Wallace, D. S. Battisti, E. J. Steig, A. J. Gallant, H. J. Kim, and L. Geng, 2014: Tropical forcing of the recent rapid Arctic warming in northeastern Canada and Greenland. Nature, 509, 209-212, https://doi.org/10.1038/nature13260. 
_- and Coauthors, 2017: Influence of high-latitude atmospheric circulation changes on summertime Arctic sea ice. Nat. Climate Change, 7, 289-295, https://doi.org/10.1038/ nclimate 3241.

__ , and Coauthors, 2019: Fingerprints of internal drivers of Arctic sea ice loss in observations and model simulations. Nat. Geosci., 12, 28-33, https://doi.org/10.1038/S41561-018-0256-8.

Dirkson, A., W. J. Merryfield, and A. Monahan, 2017: Impacts of sea ice thickness initialization on seasonal Arctic sea ice predictions. J. Climate, 30, 1001-1017, https://doi.org/10.1175/ JCLI-D-16-0437.1.

Fetterer, F., and K. Knowles, 2004: Sea ice index monitors polar ice extent. Eos, Trans. Amer. Geophys. Union, 85, 163, https://doi.org/10.1029/2004EO160007.

Fyfe, J. C., K. Von Salzen, N. P. Gillett, V. K. Arora, G. M. Flato, and J. R. McConnell, 2013: One hundred years of Arctic surface temperature variation due to anthropogenic influence. Sci. Rep., 3, 2645, https://doi.org/10.1038/srep02645.

Giorgetta, M. A., and Coauthors, 2013: Climate and carbon cycle changes from 1850 to 2100 in MPI-ESM simulations for the Coupled Model Intercomparison Project phase 5. J. Adv. Model. Earth Syst., 5, 572-597, https://doi.org/ 10.1002/jame.20038.

Henley, B. J., J. Gergis, D. J. Karoly, S. Power, J. Kennedy, and C. K. Folland, 2015: A tripole index for the interdecadal Pacific oscillation. Climate Dyn., 45, 3077-3090, https://doi.org/ 10.1007/s00382-015-2525-1.

Hoerling, M. P., J. W. Hurrell, and T. Xu, 2001: Tropical origins for recent North Atlantic climate change. Science, 292, 90-92, https://doi.org/10.1126/science.1058582.

Huang, B., and Coauthors, 2017: NOAA Extended Reconstructed Sea Surface Temperature (ERSST), version 5 [global]. NOAA National Centers for Environmental Information, accessed 12 December 2018, https://doi.org/10.7289/V5T72FNM.

Huffman, G. J., R. F. Adler, D. T. Bolvin, and G. Gu, 2009: Improving the global precipitation record: GPCP version 2.1. Geophys. Res. Lett., 36, L17808, https://doi.org/10.1029/2009GL040000.

Jahn, A., J. E. Kay, M. M. Holland, and D. M. Hall, 2016: How predictable is the timing of a summer ice-free Arctic? Geophys. Res. Lett., 43, 9113-9120, https://doi.org/10.1002/ 2016GL070067.

Kay, J. E., M. M. Holland, and A. Jahn, 2011: Inter-annual to multidecadal Arctic sea ice extent trends in a warming world. Geophys. Res. Lett., 38, L15708, https://doi.org/10.1029/ 2011 GL048008.

— , and Coauthors, 2015: The Community Earth System Model (CESM) large ensemble project: A community resource for studying climate change in the presence of internal climate variability. Bull. Amer. Meteor. Soc., 96, 1333-1349, https:// doi.org/10.1175/BAMS-D-13-00255.1.

Lee, M. H., S. Lee, H. J. Song, and C. H. Ho, 2017: The recent increase in the occurrence of a boreal summer teleconnection and its relationship with temperature extremes. J. Climate, $\mathbf{3 0 ,}$ 7493-7504, https://doi.org/10.1175/JCLI-D-16-0094.1.

Lee, S., 2012: Testing of the tropically excited Arctic warming mechanism (TEAM) with traditional El Niño and La Niña. J. Climate, 25, 4015-4022, https://doi.org/10.1175/JCLI-D12-00055.1.

—_ T. Gong, N. Johnson, S. B. Feldstein, and D. Pollard, 2011: On the possible link between tropical convection and the Northern Hemisphere Arctic surface air temperature change between 1958 and 2001. J. Climate, 24, 4350-4367, https:// doi.org/10.1175/2011JCLI4003.1.
L'Heureux, M. L., A. Kumar, G. D. Bell, M. S. Halpert, and R. W. Higgins, 2008: Role of the Pacific-North American (PNA) pattern in the 2007 Arctic sea ice decline. Geophys. Res. Lett., 35, L20701, https://doi.org/10.1029/2008GL035205.

, A. Butler, B. Jha, A. Kumar, and W. Wang, 2010: Unusual extremes in the negative phase of the Arctic Oscillation during 2009. Geophys. Res. Lett., 37, L10704, https://doi.org/10.1029/ 2010GL043338.

Liu, F., J. Lu, O. Garuba, L. R. Leung, Y. Luo, and X. Wan, 2018: sensitivity of surface temperature to oceanic forcing via $q$-flux Green's function experiments. Part I: Linear response function. J. Climate, 31, 3625-3641, https://doi.org/10.1175/ JCLI-D-17-0462.1.

Livezey, R. E., and W. Y. Chen, 1983: Statistical field significance and its determination by Monte Carlo techniques. Mon. Wea. Rev., 111, 46-59, https://doi.org/10.1175/15200493(1983)111<0046:SFSAID>2.0.CO;2.

Mahlstein, I., and R. Knutti, 2012: September Arctic sea ice predicted to disappear near $2^{\circ} \mathrm{C}$ global warming above present. J. Geophys. Res., 117, D06104, https://doi.org/10.1029/2011JD016709.

Mantua, N. J., S. R. Hare, Y. Zhang, J. M. Wallace, and R. C. Francis, 1997: A Pacific interdecadal climate oscillation with impacts on salmon production. Bull. Amer. Meteor. Soc., 78, 1069-1080, https://doi.org/10.1175/1520-0477(1997)078<1069: APICOW $>2.0 . C O ; 2$.

Meehl, G. A., C. T. Chung, J. M. Arblaster, M. M. Holland, and C. M. Bitz, 2018: Tropical decadal variability and the rate of Arctic sea ice decrease. Geophys. Res. Lett., 45, 11-326, https:// doi.org/10.1029/2018GL079989.

Notz, D., and J. Stroeve, 2016: Observed Arctic sea-ice loss directly follows anthropogenic $\mathrm{CO}_{2}$ emission. Science, 354, 747-750, https://doi.org/10.1126/science.aag2345.

Olonscheck, D., T. Mauritsen, and D. Notz, 2019: Arctic sea-ice variability is primarily driven by atmospheric temperature fluctuations. Nat. Geosci., 12, 430-434, https://doi.org/10.1038/ S41561-019-0363-1.

Overland, J. E., and M. Wang, 2013: When will the summer Arctic be nearly sea ice free? Geophys. Res. Lett., 40, 2097-2101, https://doi.org/10.1002/grl.50316.

, J. A. Francis, E. Hanna, and M. Wang, 2012: The recent shift in early summer Arctic atmospheric circulation. Geophys. Res. Lett., 39, L19804, https://doi.org/10.1029/2012GL053268.

Perlwitz, J., M. Hoerling, and R. Dole, 2015: Arctic tropospheric warming: Causes and linkages to lower latitudes. J. Climate, 28, 2154-2167, https://doi.org/10.1175/JCLI-D-14-00095.1.

Plumb, R. A., 1985: On the three-dimensional propagation of stationary waves. J. Atmos. Sci., 42, 217-229, https://doi.org/ 10.1175/1520-0469(1985)042<0217:OTTDPO > 2.0.CO;2.

Post, E., and Coauthors, 2013: Ecological consequences of sea-ice decline. Science, 341, 519-524, https://doi.org/ 10.1126/science. 1235225 .

Roeckner, E., and Coauthors, 1996: The atmospheric general circulation model ECHAM-4: Model description and simulation of present-day climate. Max Planck Institute for Meteorology Rep. 218, 90 pp.

Rosenblum, E., and I. Eisenman, 2017: Sea ice trends in climate models only accurate in runs with biased global warming. J. Climate, 30, 6265-6278, https://doi.org/10.1175/JCLI-D16-0455.1.

Screen, J. A., 2018: Arctic sea ice at 1.5 and $2^{\circ}$ C. Nat. Climate Change, 8, 362-363, https://doi.org/10.1038/s41558-018-0137-6. , and J. A. Francis, 2016: Contribution of sea-ice loss to Arctic amplification is regulated by Pacific Ocean decadal 
variability. Nat. Climate Change, 6, 856-860, https://doi.org/ 10.1038/nclimate3011.

— , and C. Deser, 2019: Pacific Ocean variability influences the time of emergence of a seasonally ice-free Arctic Ocean. Geophys. Res. Lett., 46, 2222-2231, https://doi.org/10.1029/2018GL081393.

Serreze, M. C., and R. G. Barry, 2011: Processes and impacts of Arctic amplification: A research synthesis. Global Planet. Change, 77, 85-96, https://doi.org/10.1016/j.gloplacha.2011.03.004.

Stroeve, J., and D. Notz, 2018: Changing state of Arctic sea ice across all seasons. Environ. Res. Lett., 13, 103001, https:// doi.org/10.1088/1748-9326/aade56.

— , T. Markus, L. Boisvert, J. Miller, and A. Barrett, 2014: Changes in Arctic melt season and implications for sea ice loss. Geophys. Res. Lett., 41, 1216-1225, https://doi.org/10.1002/2013GL058951.

Sun, L., M. Alexander, and C. Deser, 2018: Evolution of the global coupled climate response to Arctic sea ice loss during 1990 2090 and its contribution to climate change. J. Climate, 31, 7823-7843, https://doi.org/10.1175/JCLI-D-18-0134.1.

Swart, N., 2017: Climate variability: Natural causes of Arctic seaice loss. Nat. Climate Change, 7, 239-241, https://doi.org/ 10.1038/nclimate3254.

_ J. C. Fyfe, E. Hawkins, J. E. Kay, and A. Jahn, 2015: Influence of internal variability on Arctic sea-ice trends. Nat. Climate Change, 5, 86-89, https://doi.org/10.1038/nclimate2483.

Taylor, K. E., R. J. Stouffer, and G. A. Meehl, 2012: An overview of CMIP5 and the experiment design. Bull. Amer. Meteor. Soc., 93, 485-498, https://doi.org/10.1175/BAMS-D-11-00094.1.

Tietsche, S., D. Notz, J. H. Jungclaus, and J. Marotzke, 2011: Recovery mechanisms of Arctic summer sea ice. Geophys. Res. Lett., 38, L02707, https://doi.org/10.1029/2010GL045698.

Trenberth, K. E., J. T. Fasullo, G. Branstator, and A. S. Phillips, 2014: Seasonal aspects of the recent pause in surface warming. Nat. Climate Change, 4, 911-916, https://doi.org/10.1038/nclimate2341.
Vaughan, D. G., and Coauthers, 2013: Observations: Cryosphere. Climate Change 2013: The Physical Science Basis, T. F. Stocker et al., Eds., Cambridge University Press, 317-382, https:// doi.org/10.1017/CBO9781107415324.012.

Vimont, D. J., J. M. Wallace, and D. S. Battisti, 2003: The seasonal footprinting mechanism in the Pacific: Implications for ENSO. J. Climate, 16, 2668-2675, https://doi.org/10.1175/15200442(2003)016<2668:TSFMIT>2.0.CO;2.

Wallace, J. M., C. Smith, and C. S. Bretherton, 1992: Singular value decomposition of wintertime sea surface temperature and 500mb height anomalies. J. Climate, 5, 561-576, https://doi.org/ 10.1175/1520-0442(1992)005<0561:SVDOWS >2.0.CO;2.

Wernli, H., and L. Papritz, 2018: Role of polar anticyclones and midlatitude cyclones for Arctic summertime sea-ice melting. Nat. Geosci., 11, 108-113, https://doi.org/10.1038/s41561-017-0041-0.

Wettstein, J. J., and C. Deser, 2014: Internal variability in projections of twenty-first-century Arctic sea ice loss: Role of the large-scale atmospheric circulation. J. Climate, 27, 527-550, https://doi.org/10.1175/JCLI-D-12-00839.1.

Wills, R. C., T. Schneider, J. M. Wallace, D. S. Battisti, and D. L. Hartmann, 2018: Disentangling global warming, multidecadal variability, and El Niño in Pacific temperatures. Geophys. Res. Lett., 5, 2487-2496, https://doi.org/10.1002/2017GL076327.

Winton, M., 2011: Do climate models underestimate the sensitivity of Northern Hemisphere sea ice cover? J. Climate, 24, 39243934, https://doi.org/10.1175/2011JCLI4146.1.

Yang, W., and G. Magnusdottir, 2018: Year-to-year variability in Arctic minimum sea ice extent and its preconditions in observations and the CESM large ensemble simulations. Sci. Rep., 8, 9070, https://doi.org/10.1038/s41598-018-27149-y.

Zhang, R., 2015: Mechanisms for low-frequency variability of summer Arctic sea ice extent. Proc. Natl. Acad. Sci. USA, 112, 4570-4575, https://doi.org/10.1073/pnas.1422296112. 